\title{
Theoretical Modelling Analysis on Tensile Properties of Bioepoxy/Clay Nanocomposites Using Epoxidised Soybean Oils
}

\author{
Haipan Salam $\mathbb{D}^{1,2}$ and Yu Dong $\mathbb{D}^{2}$ \\ ${ }^{1}$ Department of Mechanical Engineering Education, Universitas Pendidikan Indonesia, Bandung, 40153 West Java, Indonesia \\ ${ }^{2}$ School of Civil and Mechanical Engineering, Curtin University, GPO Box U1987, Perth, WA 6845, Australia \\ Correspondence should be addressed to Yu Dong; y.dong@curtin.edu.au
}

Received 9 July 2019; Accepted 21 October 2019; Published 2 December 2019

Academic Editor: Hassan Karimi-Maleh

Copyright ( 2019 Haipan Salam and Yu Dong. This is an open access article distributed under the Creative Commons Attribution License, which permits unrestricted use, distribution, and reproduction in any medium, provided the original work is properly cited.

\begin{abstract}
A theoretical modelling framework was proposed to predict tensile moduli and tensile strengths of bioepoxy/clay nanocomposites in terms of clay content and epoxidised soybean oil (ESO) content, which could be influenced by properties of blended matrices in nanocomposites, clay filler type, orientation and dispersion status, clay morphological structures, and filler-matrix interfacial bonding. The random orientation of dispersed clay fillers played a significant role in predicting elastic moduli of bioepoxy/clay nanocomposites at clay contents of 1-8 wt\% (ESO content: $20 \mathrm{wt} \%$ ) according to Hui-Shia (H-S) laminate model and HalpinTsai (H-T) laminate model. In addition, when clay content was fixed at $5 \mathrm{wt} \%$, H-S laminate model coincided well with the experimental data of bioepoxy/clay nanocomposites at the ESO contents of 0-40 wt\%. Whereas, Hirsch model showed closer estimated values with experimental data at the ESO content of $60 \mathrm{wt} \%$. Finally, Turcsányi-Pukànszky-Tüdõs (T-P-T) model predicted better tensile strengths of bioepoxy/clay nanocomposites at clay contents of 1-5 wt\% (ESO content: $20 \mathrm{wt} \%$ ) and at an ESO content of 20-60 wt\% (clay content: $5 \mathrm{wt} \%$ ).
\end{abstract}

\section{Introduction}

The depletion of fossil fuel stock and plastic waste is a critical issue in recent years with urgent actions required to utilise other alternative resources from natural polymers that can substitute for derived petroleum-based polymers $[1,2]$. Researchers have shown enormous interests in bioepoxies because of their similar triglyceride epoxy side groups equivalent to conventional epoxy resins [3-6]. Bioepoxy polymers, such as epoxidised plant oils, are produced from derived plant oils and usually employed as lubricants and plasticisers for polyvinyl chloride (PVC) [3, 5, 7-13]. Epoxidised plant oils based on soybean and linseed are commercially available in large volumes with a reasonable price. Among these, epoxidised soybean oil (ESO) has been widely investigated in the manufacture of polymer composites due to its abundance, inexpensiveness, and high reactivity as comonomers when combined with other monomer-based plant oils to form crosslinking networks $[11,14,15]$.
With respect to mechanical properties, the substitution of petroleum-based epoxy resin with ESO exhibits an improvement of fracture toughness and impact strength, not mentioning the decreases in tensile modulus and tensile strength of bioepoxy blends. Several studies have investigated the effect of additional ESO to undermine mechanical properties of epoxy resins such as their tensile strengths and tensile moduli $[16,17]$, flexural strengths and flexural moduli [17], and hardness [8] for ESO/diglycidyl ether of bisphenol A (DGEBA) blends, glass transition temperature $\left(T_{g}\right)$ and storage modulus of epoxidised canola oil (ECO)/DGEBA blends [5], and thermal properties of epoxidised vegetable oil (EVO)/DGEBA blends [18]. To overcome those drawbacks mentioned earlier, the incorporation of rigid nanofillers such as nanoclays can enhance mechanical and thermal properties of bioepoxy resins and further extend the widespread applications of these nanocomposites [19-21]. High surface areas of well-dispersed and plateletlike clay nanostructures are believed to improve mechanical 
properties of bioepoxy nanocomposites, as evidenced by their higher tensile strengths and tensile moduli to a certain extent when compared with those of neat biopolymers [22-25].

Mechanical properties of bionanocomposites reinforced with nanoclays are well-understood to be affected by the compatibility and reactivity of coupling agents including biopolymers, their catalysts, and nanoclay fillers, as well as associated manufacturing methods and processing parameters [24-30]. The good compatibility between polymer matrices and their catalysts enables to improve the crosslinking density of resulting nanocomposites. Moreover, the compatibility between matrices and nanoclays can also influence their adhesion or interfacial bonding [31]. Obviously, the modification of clay interlayers also further improves clay compatibility by means of increasing interfacial interactions between matrices and clay interlayers. Indeed, the tensile strengths of nanocomposites strongly depend on the good interfacial interaction between nanoclays and polymer matrices in order to achieve effective stress transfer from nanofillers to matrices accordingly [32-39].

On the other hand, clay wettability within epoxy matrices is also critical to achieve desirable mechanical properties of epoxy/clay nanocomposites, which are mainly attributed to homogeneous clay dispersion and favourable clay orientation $[40,41]$. Other factors to influence mechanical properties of nanocomposites consist of clay content, clay aspect ratio, clay stiffness, and the dispersion and orientation of clay nanofillers [42-44]. Miyagawa et al. [45] investigated the effect of dispersion structures of organo-montmorillonite (MMT) nanoclays on elastic modulus, impact strength, and fracture properties of epoxidised linseed oil (ELO)/epoxy nanocomposites and ESO/epoxy nanocomposites. The addition of $5 \mathrm{wt} \%$ organoclays with exfoliated structures was found to improve the storage modulus by approximately $30 \%$. On the contrary, intercalated nanocomposites reinforced with $5 \mathrm{wt} \%$ organoclays only yielded 8 and $29 \%$ increases in fracture toughness when compared with those exfoliated nanocomposites and neat epoxy, respectively.

In this study, the correlation between theoretical models based on composite theory and experimental data obtained was holistically evaluated in order to successfully predict tensile moduli and tensile strengths of bioepoxy/clay nanocomposites based on ESO by considering several factors such as clay content, clay orientation, clay aspect ratio, and ESO content in bioepoxy matrices. It is anticipated to eventually offer an appropriate guidance to the manufacture of bioepoxy/clay nanocomposites in order to replace the "trial and error" method used for the valid estimation of nanocomposite properties.

\section{Theoretical Models of Polymer/Clay Nanocomposites}

Modelling approaches employed for polymer nanocomposite systems generally consist of three categories of molecularscaled, microscaled, and meso-/macroscaled methods according to different size effects [46]. Molecular-scaled methods focus on molecular dynamics, Monte Carlo method, and molecular mechanics for atoms, molecules, or clusters of the units. On the other hand, microscaled methods tend to link up the gap between the molecular-scaled method and meso-/macroscaled methods. It is well known that composite constituents are not only affected on the molecular-scaled level, but also at the microscopic scale to investigate the evolution of structures, bulk flow of materials, and the bonding interaction between matrices and fillers. Various methods such as Brownian dynamics, dissipative particle dynamics, lattice Boltzmann method, the time-dependent Ginsburg-Landau theory, and dynamic density functional theories have been developed to study microscopic structures and the interaction of composite constituents [46]. In particular, the continuum method has been considered as the most popular one among the meso-/macroscaled methods under the combination condition of both molecular structures and material nature with the homogenisation at different scaled levels. Such a method concentrates on the deformation of composite materials influenced by externally applied loads and their resulting stresses and strains. Macroscaled methods follow essential laws for the continuity of mass; the equilibrium of force, energy, and momentum; and conservation of energy and conservation of entropy [46]. Modelling and numerical simulations have been used to evaluate continuum methods including micromechanical models, equivalent-continuum models, selfconsistent models, and finite element analysis. In this study, we only discussed the application of micromechanical models in predicting tensile properties of bioepoxy/clay nanocomposites in terms of their tensile moduli and tensile strengths based on the effect of individual nanocomposite constituents. Six theoretical models, namely, Voigt and Reuss models, Hirsch model, Halpin-Tsai (H-T) model, modified $\mathrm{H}-\mathrm{T}$ models, Hui-Shia (H-S) model, and laminate model, were applied to predict tensile moduli of bionanocomposites. On the other hand, the estimation of their tensile strengths was based on Danusso-Tieghi (D-T) model, Nicolais-Nicodemo (N-N) model, Lu model, and TurcsányiPukànszky-Tüdõs (T-P-T) model. All modelling results were compared with corresponding experimental data to validate the feasibility of relevant theoretical models used as an essential guidance for nanocomposite manufacturing.

\subsection{Modulus of Polymer Particulate Composites}

2.1.1. Rule of Mixture (ROM). Rule of mixture (ROM) comprises a fundamental concept for micromechanical modelling in polymer particulate composite systems. ROM is based on the assumption that both fillers and polymer matrices are linearly elastic with the symmetry of fillers including filler shape, size and aspect ratio, and good interfacial bonding existing between fillers and matrices [46]. Voigt and Reuss models are deemed as the upper and lower bonds of ROM, respectively, in the theoretical prediction of composite systems. Voigt model involves the combination of overall composite constituents influenced by the average elastic modulus and volume fraction of each constituent, namely, parallel model [47]. Furthermore, it is also assumed that an isostrain condition takes place for both fillers and matrices 
in this upper bound, resulting in the modulus of composites given by

$$
E_{\mathrm{c}}=E_{\mathrm{p}} \varnothing_{\mathrm{p}}+E_{\mathrm{m}}\left(1-\varnothing_{\mathrm{p}}\right) .
$$

In contrast, Reuss model or series model is regarded as the inverse ROM or lower bound of ROM. It is based on the assumption that uniform stress occurs in both matrices and fillers [48]. Reuss model can be written in the following equations:

$$
E_{\mathrm{c}}=\frac{E_{\mathrm{p}} E_{\mathrm{m}}}{E_{\mathrm{m}} \varnothing_{\mathrm{p}}+E_{\mathrm{p}}\left(1-\varnothing_{\mathrm{p}}\right)},
$$

with

$$
\begin{aligned}
\phi_{\mathrm{p}} & =\frac{W_{\mathrm{p}}}{W_{\mathrm{p}}+\left(\rho_{\mathrm{p}} / \rho_{\mathrm{m}}\right)\left(1-W_{\mathrm{p}}\right)}, \\
\rho_{\text {blend }} & =\rho_{1} \varnothing_{1}+\rho_{2} \phi_{2},
\end{aligned}
$$

where $\phi_{\mathrm{p}}$ is the volume fraction of fillers in composites, $W_{\mathrm{p}}$ is the weight fraction of fillers, and $\rho_{\mathrm{m}}$ and $\rho_{\mathrm{p}}$ are densities of matrices and fillers, respectively, which can be obtained from the technical data sheet provided by the material supplier (Table 1$)$. For the density of matrix blends $\left(\rho_{\text {blend }}\right)$, it is calculated according to Equation (4) that is influenced by the densities $\left(\rho_{1}\right.$ and $\left.\rho_{2}\right)$ and corresponding volume fractions $\left(\phi_{1}\right.$ and $\phi_{2}$ ) of two constituents in blend matrices. In addition, $E_{\mathrm{c}}, E_{\mathrm{m}}$, and $E_{\mathrm{p}}$ are the moduli of composites, matrices, and fillers, respectively. In this study, $E_{\mathrm{m}}$ of bioepoxy blends was determined based on the experimental results obtained from tensile tests of bioepoxy blends at different ESO contents.

On the other hand, elastic modulus of fillers $\left(E_{\mathrm{p}}\right)$ can vary according to different clay dispersion statuses within bioepoxy matrices in nanocomposite systems. For exfoliated clay structures, $E_{\mathrm{p}}$ is given by $178 \mathrm{GPa}$, which is the modulus of the single clay platelet layer [54]. In addition, with respect to intercalated clay structures, the estimation of effective modulus of clay fillers would be different and can be calculated by applying ROM $[54,55]$ as follows:

$$
\begin{aligned}
E_{\text {intercalation }} & =E_{\mathrm{MMT}} \varnothing_{\mathrm{MMT}}+E_{\text {gallery }}\left(1-\varnothing_{\mathrm{MMT}}\right), \\
\text { if } E_{\text {gallery }} & \ll E_{\mathrm{MMT}}, \\
E_{\text {intercalation }} & \approx E_{\mathrm{MMT}} \varnothing_{\mathrm{MMT}} \approx\left(\frac{d_{\mathrm{MMT}}}{d_{002}}\right) E_{\mathrm{MMT}},
\end{aligned}
$$

where $\phi_{\mathrm{MMT}}$ and $E_{\mathrm{MMT}}$ are the volume fraction in MMT stacks and elastic modulus of MMT, respectively, while $E_{\text {gallery }}$ is the gallery (interlayer) modulus. When the gallery modulus is much smaller than MMT modulus $\left(E_{\text {gallery }} \ll E_{\mathrm{MMT}}\right), E_{\text {gallery }}$ would make an insignificant contribution to the modulus of intercalated clay structures.
Accordingly, the modulus of intercalated clay structures can be approximated to be in the expression of Equation (6) in terms of $d$-spacing obtained from XRD results. Based on $\mathrm{XRD}$ and TEM results, clay structures have been formed with the combination of dominantly intercalated, exfoliated, and aggregated clay structures in our prepared bioepoxy/clay nanocomposites [56]. The interlayer spacing $d_{002}$ of clay fillers was selected demonstrating a shifting interlayer spacing of clay platelet layers. As such, effective moduli of intercalated clay fillers at different filler contents and ESO contents were determined, as listed in Table 2.

2.1.2. Modified Rule of Mixture (MROM). In general, ROM is limited to the effect of elastic moduli and volume fractions of composite constituents while filler shape, filler orientation, and 3D spatial position of fillers are usually not considered. In fact, the latter more or less undermines elastic moduli of composite materials, which can be compensated for with the incorporation of modulus reduction factor (MRF) in MROM [57]. This is particularly the case in using the MRF along with filler aspect ratio $(\alpha)$ [58] when imperfect filler orientation in composite materials is taken into account. As such, MROM can be given by

$$
E_{\mathrm{c}}=E_{\mathrm{p}} \varnothing_{\mathrm{p}}(\mathrm{MRF})+E_{\mathrm{m}}\left(1-\varnothing_{\mathrm{p}}\right)
$$

The determination of MRF can be based on two different forms for flake-like fillers in composites, namely, Riley's rule [59] and Padawer and Beecher's rule [60] as follows:

Riley's rule:

$$
(\mathrm{MRF})=1-\frac{\ln (u+1)}{u},
$$

Padawer and Beecher's rule:

$$
(\mathrm{MRF})=\frac{\tanh u}{u}
$$

with

$$
u=\frac{1}{\alpha} \sqrt{\frac{\phi_{\mathrm{p}} G_{\mathrm{m}}}{E_{\mathrm{p}}\left(1-\phi_{\mathrm{p}}\right)}},
$$

in which $G_{\mathrm{m}}$ is the shear modulus of the matrix and $\alpha$ is the aspect ratio of fillers in composite systems. Wu et al. [58] investigated the MRF of rubber/clay nanocomposites by fitting corresponding experimental data. It was found that $\mathrm{MRF}=0.66$ could better fit experimental data for the modulus prediction when the filler volume fraction was less than 6 vol\%.

2.1.3. Hirsch Model. Hirsch [61] proposed a model for estimating the elastic modulus of composites with the combination of parallel and series models. The general form of such 
TABLE 1: Material properties of epoxy resin, ESO, and Cloisite 15 clays in bionanocomposites.

\begin{tabular}{|c|c|c|}
\hline Material & Properties & Reference \\
\hline \multirow{4}{*}{ DGEBA } & Epoxy equivalent weight (EEW): 190-195 g/eq & \multirow{4}{*}[49,50]{} \\
\hline & Molecular weight: $340.42 \mathrm{~g} / \mathrm{mol}$ & \\
\hline & Density: $1.17 \mathrm{~g} / \mathrm{cm}^{3}$ & \\
\hline & Viscosity: $\sim 11.000 \mathrm{mPa} \cdot \mathrm{s}$ & \\
\hline \multirow{4}{*}{ ESO } & Oxirane content: $6.2 \%$ & \multirow{4}{*}[51,52]{} \\
\hline & Molecular weight: $975.40 \mathrm{~g} / \mathrm{mol}$ & \\
\hline & Density: $0.982 \mathrm{~g} / \mathrm{cm}^{3}$ & \\
\hline & Viscosity: $325 \mathrm{mPa} \cdot \mathrm{s}$ & \\
\hline \multirow{6}{*}{ Cloisite 15} & Organo-modified MMT clay & \multirow{5}{*}[53]{} \\
\hline & Bis(hydrogenated tallow alkyl) dimethyl, salt & \\
\hline & $d_{001}=3.63 \mathrm{~nm}$ & \\
\hline & Cation exchange capacity $($ CEC $)=125 \mathrm{meq} / 100 \mathrm{~g}$ & \\
\hline & Density $\rho=1.66 \mathrm{~g} / \mathrm{cm}^{3}$ & \\
\hline & $E_{\mathrm{MMT}}=178 \mathrm{GPa}$ for single MMT platelet & {$[54]$} \\
\hline
\end{tabular}

TABle 2: Effective modulus of intercalated clay particles in bionanocomposites (ESO content: $20 \mathrm{wt} \%$ ).

\begin{tabular}{lcc}
\hline Clay filler content & \multicolumn{2}{c}{ Bionanocomposites with 20 wt\% ESO } \\
\hline (wt\%) & $d_{002}(\mathrm{~nm})[56]$ & $E_{\text {intercalation }}(\mathrm{GPa})$ \\
1 & 1.97 & 85.06 \\
3 & 1.96 & 85.59 \\
5 & 1.96 & 85.59 \\
8 & 1.96 & 85.59 \\
\hline
\end{tabular}

an equation is the effect of matrix modulus, the modulus of fillers, and their volume fractions along with an empirical constant $x$. Hirsch model equation is given by

$$
E_{\mathrm{c}}=x\left(E_{\mathrm{m}}\left(1-\varnothing_{\mathrm{p}}\right)+E_{\mathrm{p}} \varnothing_{\mathrm{p}}\right)+(1-x) \frac{E_{\mathrm{p}} E_{\mathrm{m}}}{E_{\mathrm{m}} \varnothing_{\mathrm{p}}+E_{\mathrm{p}}\left(1-\varnothing_{\mathrm{p}}\right)},
$$

where $x$ is an empirical constant to control the stress transfer between fillers and matrices in composites, which is based on the curve fitting with experimental data $(0<x<1)$. " $x$ " is regarded as a significant parameter in predicting elastic moduli of nanocomposites, which can also determine the filler orientation of nanocomposites.

2.1.4. Halpin-Tsai Model. Halpin-Tsai (H-T) model $[62,63]$ offers a reasonable prediction for elastic moduli of unidirectional composites with respect to volume fraction and geometry of fillers. H-T model is generally used for continuous or discontinuous fillers such as fibre-like or flake-like fillers with different alignment directions. The elastic modulus of composites can be expressed in the following form:

$$
E_{\mathrm{c}}=E_{\mathrm{m}} \frac{1+\xi \eta_{\mathrm{L}} \varnothing_{\mathrm{p}}}{1-\eta_{\mathrm{L}} \varnothing_{\mathrm{p}}}
$$

where $E_{\mathrm{c}}, E_{\mathrm{m}}$, and $E_{\mathrm{p}}$ represent the elastic moduli of composites, matrices, and fillers, respectively, and $\eta_{\mathrm{L}}$ is given by

$$
\eta_{\mathrm{L}}=\frac{\left(E_{\mathrm{p}} / E_{\mathrm{m}}\right)-1}{\left(E_{\mathrm{p}} / E_{\mathrm{m}}\right)+\xi}
$$

where $\xi$ is a constant depending on the geometry and aspect ratios of fillers in composites. $\xi$ can be given in the following forms [54]:

$$
\begin{aligned}
& \xi=2 \alpha=2\left(\frac{l}{t}\right) \text { for longitudinal modulus }\left(E_{11}\right), \\
& \xi=2 \text { for transverse modulus }\left(E_{22}\right),
\end{aligned}
$$

in which $l$ and $t$ are the length and thickness/depth of dispersed fillers in composites, respectively. In addition, when $\xi$ is very large $(\xi \longrightarrow \infty)$, H-T model is equal to ROM (i.e., a parallel model), as given in Equation (1). Contrarily, when $\xi$ is very small $(\xi \longrightarrow 0)$, H-T model becomes an inverse model of ROM (i.e., series model) presented in Equation (2). Thus, H-T model can be used for most prediction situations between lower and upper limits in ROM.

On the other hand, in polymer/clay nanocomposite system, H-T model can be used to predict elastic moduli of nanocomposites influenced by volume fraction and aspect ratio of clay fillers as well as clay dispersion status in nanocomposites [54, 55, 64]. In completely exfoliated clay structures, the prediction of elastic modulus of nanocomposites would be calculated using Equation (11) with $E_{\mathrm{p}} / E_{\mathrm{m}}$ being equal to the ratio of the modulus of single clay platelet layer to matrix modulus. In addition, for an intercalated clay structure system, elastic modulus prediction is also determined according to Equation (11), but $E_{\mathrm{p}} / E_{\mathrm{m}}$ can change and become the ratio of elastic modulus of platelet stacks to that of matrices. The elastic modulus of intercalated clay 
structures can be calculated based on Equation (6). On the contrary, for randomly oriented clay platelets, the elastic modulus of nanocomposites can be calculated using the combination of longitudinal modulus $\left(E_{11}\right)$ and transverse modulus $\left(E_{22}\right)$ of nanocomposites with the same aspect ratio and volume fraction of clay fillers, as given below [64, 65]:

$$
E_{\mathrm{c}}=E_{\mathrm{m}}\left[\frac{3}{8} E_{11}+\frac{5}{8} E_{22}\right]
$$

or

$$
E_{\mathrm{c}}=E_{\mathrm{m}}\left[\frac{3\left(1+\xi \eta_{\mathrm{L}} \phi_{\mathrm{p}}\right)}{8\left(1-\eta_{\mathrm{L}} \varnothing_{\mathrm{p}}\right)}+\frac{5\left(1+2 \eta_{\mathrm{T}} \phi_{\mathrm{p}}\right)}{8\left(1-\eta_{\mathrm{T}} \phi_{\mathrm{p}}\right)}\right]
$$

with

$$
\begin{gathered}
\eta_{\mathrm{T}}=\frac{\left(E_{\mathrm{p}} / E_{\mathrm{m}}\right)-1}{\left(E_{\mathrm{p}} / E_{\mathrm{m}}\right)+2}, \\
\xi=\frac{2}{3} \alpha=\left(\frac{2 l}{3 t}\right) .
\end{gathered}
$$

Additionally, 2D structure shape of clay platelets can possibly make less contribution to the modulus of nanocomposites as compared with those filled by $1 \mathrm{D}$ fibre-like counterparts. Thus, the MRF for clay platelet fillers is incorporated in modified H-T model according to Equations (12) and (16), which are presented below accordingly:

$$
\begin{aligned}
& E_{\mathrm{c}}=E_{\mathrm{m}} \frac{1+\xi(\mathrm{MRF}) \eta_{\mathrm{L}} \varnothing_{\mathrm{p}}}{1-\eta_{\mathrm{L}} \varnothing_{\mathrm{p}}}, \\
& E_{\mathrm{c}}=E_{\mathrm{m}}\left[\frac{3\left(1+\xi(\mathrm{MRF}) \eta_{\mathrm{L}} \phi_{\mathrm{p}}\right)}{8\left(1-\eta_{\mathrm{L}} \varnothing_{\mathrm{p}}\right)}+\frac{5\left(1+2(\mathrm{MRF}) \eta_{\mathrm{T}} \phi_{\mathrm{p}}\right)}{8\left(1-\eta_{\mathrm{T}} \phi_{\mathrm{p}}\right)}\right] .
\end{aligned}
$$

2.1.5. Hui-Shia (H-S) Model. Hui-Shia (H-S) model develops the prediction of elastic modulus of unidirectionally aligned two-phase composites with fibre-like or flakelike filler inclusions $[57,66]$. H-S model simplifies the orientation of fillers based on the assumption of perfect interfacial bonding between matrices and fillers with similar Poisson's ratios. The associated elastic modulus equations are given below:

Longitudinal elastic modulus $\left(E_{11}\right)$ :

$$
\frac{E_{\mathrm{c}}}{E_{\mathrm{m}}}=\frac{E_{11}}{E_{\mathrm{m}}}=\frac{1}{1-\left(\phi_{\mathrm{p}} / 4\right)\left[\left(1 / \xi^{\prime}\right)+3 /\left(\xi^{\prime}+\Lambda\right)\right]},
$$

Transverse elastic modulus $\left(E_{22}\right)$ :

$$
\frac{E_{\mathrm{c}}}{E_{\mathrm{m}}}=\frac{E_{22}}{E_{\mathrm{m}}}=\frac{1}{1-\left[\phi_{\mathrm{p}} / \xi^{\prime}\right]}
$$

with

$$
\xi^{\prime}=\phi_{\mathrm{p}}+\frac{E_{\mathrm{m}}}{E_{\mathrm{p}}-E_{\mathrm{m}}}+3\left(1-\phi_{\mathrm{p}}\right)\left[\frac{(1-g) \alpha^{\prime 2}-(g / 2)}{\alpha^{\prime 2}-1}\right]
$$

$$
\Lambda=\left(1-\phi_{\mathrm{p}}\right)\left[\frac{3\left(\alpha^{\prime 2}+0.25\right) g-2 \alpha^{\prime 2}}{\alpha^{\prime 2}-1}\right]
$$

where $\alpha^{\prime}$ is the inverse of aspect ratio $\alpha$ or the ratio of thickness to the length of fillers (i.e., $\alpha^{\prime} \approx \mathrm{t} / l$ ), and $g$ is a geometric parameter of composites defined in Equations (23), (24), and (25). In case of $\alpha^{\prime} \approx 1, g=2 / 3 . \alpha^{\prime} \geq 1$ belongs to the inclusion of fibre-like fillers while $\alpha^{\prime} \leq 1$ is used for the inclusion of flake-like or disk-like fillers according to Equation (26). In addition, for a perfect interface, $g$ would be given in Equation (27).

$$
g=\left\{\begin{array}{l}
\frac{\alpha^{\prime}}{\left(\alpha^{\prime 2}-1\right)^{3 / 2}}\left[\alpha^{\prime}\left(\alpha^{\prime 2}-1\right)^{1 / 2}-\cosh ^{-1} \alpha^{\prime}\right] \alpha^{\prime} \geq 1 \\
\frac{\alpha^{\prime}}{\left(1-\alpha^{\prime 2}\right)^{3 / 2}}\left[-\alpha^{\prime}\left(1-\alpha^{\prime 2}\right)^{1 / 2}+\cos ^{-1} \alpha^{\prime}\right] \alpha^{\prime} \leq 1,
\end{array}\right.
$$

$$
g=\left(\frac{\pi}{2}\right) \alpha^{\prime}
$$

2.1.6. Laminate Model. Laminate model is developed with respect to geometric properties of filler inclusions in matrices. From the experimental point of view, typical fillers in composites are generally subjected to random orientation or misalignment, as compared with unidirectionally aligned reinforcements. The aspect ratio and modulus of fillers, as well as the orientation of dispersed fillers have a significant effect on elastic moduli of composites [54]. In case of fully random orientation in the $3 \mathrm{D}$ orthogonal direction, platelet-like fillers would induce more effective planar reinforcements as opposed to fibre-like fillers. The related equations based on fibre-like or platelet-like fillers are proposed as follows $[67,68]$ :

$$
\begin{aligned}
& E_{\text {ran-3D }}^{\text {fibre }}=0.184 E_{11}+0.816 E_{22}, \\
& E_{\text {ran-3D }}^{\text {platelet }}=0.49 E_{11}+0.51 E_{22},
\end{aligned}
$$

where $E_{11}$ and $E_{22}$ are longitudinal and transverse moduli of composites, respectively. 


\subsection{Strength of Polymer Particulate Composites}

2.2.1. Danusso-Tieghi (D-T) Model. Danusso and Tieghi [69] proposed a relationship of mechanical strength and volume fraction of rigid matrix-based composites. It is assumed in Danusso and Tieghi (D-T) model that there is no adhesion between matrices and fillers, resulting from no load transfer from matrices to fillers. Thus, the total load is equal to that carried by matrices alone. In addition, D-T model can be applied from regular or irregular filler distribution to random filler dispersion. Nonetheless, this model can also be used with the existing adhesion. A simple equation for the strength of composites is given by:

$$
\sigma_{\mathrm{c}}=\sigma_{\mathrm{m}}(1-\psi)
$$

where $\sigma_{\mathrm{c}}$ and $\sigma_{\mathrm{m}}$ are tensile strengths of composites and matrices, respectively, and $\psi$ is the area fraction in the cross section. With those aforementioned model assumptions and random orientation of filler structures, the area fraction of the matrix must be the same for any cross section through the matrix, for which the area fraction of the matrix's cross section is equal to the volume fraction of fillers $\left(\psi \approx \phi_{\mathrm{p}}\right)$ $[69,70]$.

2.2.2. Nicolais and Narkis (N-N) Model. This model is based on previous $\mathrm{D}-\mathrm{T}$ model by replacing the volume fraction with a power law function in terms of volume fraction as follows [71]:

$$
\sigma_{\mathrm{c}}=\sigma_{\mathrm{m}}\left(1-a \phi_{\mathrm{p}}^{b}\right)
$$

where $a$ and $b$ are constants influenced by particle shape and arrangement in composites. Based on the hypothesis that there is no adhesion between matrices and fillers, Nicolais and Narkis (N-N) model is considered for cubic filler shape with uniformly dispersed spherical particles. However, it is assumed that a minimum cross section of continuous phase should be perpendicular to the applied load. Thus, the strength of composites is calculated according to the equation below:

$$
\sigma_{\mathrm{c}}=\sigma_{\mathrm{m}}\left(1-1.21 \phi_{\mathrm{p}}^{2 / 3}\right)
$$

It is used to predict the lower-bound strength of composites. In addition, for their upper bound, the strength is calculated with the assumption of perfect adhesion between matrices and fillers. As such, the strength of composites is the same as that of the matrix or unfilled polymer $\left(\sigma_{c} \approx \sigma_{m}\right)$.

2.2.3. Lu Model. Lu model [72] has been developed by modifying N-N model when there is some adhesion existing between matrices and fillers, which is given by:

$$
\sigma_{\mathrm{c}}=\sigma_{\mathrm{m}}\left(1-1.07 \phi_{\mathrm{p}}^{2 / 3}\right)
$$

This equation is established by using the combined properties from micromechanical measurement, microdamage monitoring, and micromechanical analysis in order to obtain the interfacial bonding strength between matrices and fillers.

2.2.4. Turcsányi-Pukànszky-Tüdõs (T-P-T) Model. Turcsányi et al. [73] proposed a semiempirical equation for very strong particle-matrix interfacial bonding with a simple hyperbolic function to describe the change of filler cross section with the filler content, which is known as the TurcsányiPukànszky-Tüdõs (T-P-T) model [74-76]. Nonetheless, the functionalisation of exponential function is subjected to the unexpected dependence of the matrix strength and filler volume fraction. Additionally, T-P-T model can be applied to composites with the inclusion of spherical particles and anisotropic particles. The equation is generally formulated as follows:

$$
\sigma_{\mathrm{c}}=\left[\frac{1-\phi_{\mathrm{p}}}{1+2.5 \phi_{\mathrm{p}}} \sigma_{\mathrm{m}}\right] \exp \left(B \phi_{\mathrm{p}}\right)
$$

where $\sigma_{\mathrm{m}}$ and $\phi_{\mathrm{p}}$ are the strength of matrices and volume fraction of fillers, respectively. $B$ is a constant that depends on the surface area of particles, their density, and interfacial bonding with matrices. If $B=0$, the fillers act as voids having poor interfacial bonding without adhesion and load transfer at the matrix-filler interface. Nonetheless, if $B \leq 3$, the filler-matrix interface is weak without reinforcing effect. The constant $B$ was calculated by fitting experimental data with theoretical results and derived from the minimum sum of squares of variance from experimental data of composite strengths.

\section{Result and Discussion}

\subsection{Tensile Modulus of Bionanocomposites}

3.1.1. Effect of Clay Content. Theoretical models according to Equations (1) to (29) were used to predict the effect of clay content on tensile moduli of bioepoxy/clay nanocomposites cured by isophorone diamine (IPDA) determined in our previous study [56]. Material properties of bionanocomposite constituents including the moduli of single platelet MMT $\left(E_{\mathrm{MMT}}\right)$, DGEBA as a conventional epoxy resin, and ESO as well as the molecular weight and density of matrices (i.e., DGEBA resin and ESO) and Cloisite 15 clay nanofillers are listed in Table 1. In addition, Equation (6) was used to calculate the effective elastic modulus of intercalated clay structures detected in bionanocomposites. The $d$-spacing values of intercalated clay structures were obtained according to previous XRD results [56]. The calculation results for effective elastic moduli of intercalated clay structures in bionanocomposites are listed in Table 2, which was used to estimate theoretical elastic moduli of bionanocomposites at different clay contents. Additionally, with respect to the random orientation of clay structures, 3D platelet-like filler laminate model was employed to incorporate actual filler geometries. Nonetheless, $\mathrm{MRF} \approx 0.66$ [58] was also implemented based on a mix of partially intercalated/exfoliated and aggregated clay structures in bionanocomposites by assumption. The abovementioned geometric parameters including clay 
orientation and dispersion status were determined according to previous results [56] obtained from TEM micrographs of bionanocomposites cured by IPDA at a fixed ESO content of $20 \mathrm{wt} \%$, as shown in Figure 1.

Theoretical prediction of elastic moduli of bioepoxy/clay nanocomposites as a function of clay content was compared with experimental data, as illustrated in Figures 2-4. In Figure 2, it can be seen that Voigt model demonstrated an overestimated result as opposed to experimental data despite the inclusion of MRF. On the contrary, the theoretical prediction of elastic modulus by Reuss model, which is known as inverse Voigt model, presented an underestimation for experimental data instead. Voigt and Reuss models only give a rough estimation for elastic moduli of bionanocomposites, thus demonstrating their upper and lower bounds, respectively. This phenomenon indicated that those two models neglected the geometry, dispersion status, and orientation of fillers, which further made the theoretical prediction become questionable. In order to enhance the prediction accuracy, filler geometric parameters, filler dispersion status, and relevant orientation were taken into account by utilising Hirsch model and H-T model. It is assumed in Hirsch model that the random orientation of clay fillers takes place with the combination of parallel and series filler orientations in bionanocomposites. The curve fitting with experimental data by Hirsch model revealed better agreement with experimental data when compared with those predicted by Voigt and Reuss models. Nonetheless, it has been found that $x=0.029$ for parallel filler orientation to the stress direction. This can be indicated that the series orientation of clay platelet fillers is significantly affected by the behaviour of bionanocomposites in real experiments.

On the other hand, in order to enhance the accuracy of geometric parameters, $\mathrm{H}$-T model and modified $\mathrm{H}$-T model as well as modified equations with the incorporation of MRF were employed in predicting elastic moduli of bionanocomposites at the ESO content of $20 \mathrm{wt} \%$ by varying aspect ratios of fillers according to Equations (13) to (21) and (29), respectively. Figure 3 presented the theoretical prediction and experimental data for elastic moduli of bionanocomposites according to $\mathrm{H}-\mathrm{T}$ model and modified $\mathrm{H}-\mathrm{T}$ laminate model. Figure 3(a) showed that increasing the aspect ratio, from 3 to 60 , improved the estimated elastic moduli in line with increasing the clay content owing to the enhanced wettability and contact surface areas between clay fillers and matrices. The lower clay content yields higher filler aspect ratios as expected. Nonetheless, the use of MRF in H-T laminate model with random orientation exhibited a reduction in predicted elastic moduli, which could eventually affect the prediction of aspect ratios for clay fillers. The percentage difference between experimental data and theoretical results was ranging from 2 to $8.7 \%$ and $0.7-2.7 \%$ for $\mathrm{H}-\mathrm{T}$ laminate model and $\mathrm{H}$-T laminate model with MRF, respectively. Similar approaches were also revealed for the theoretical prediction of elastic moduli of nanocomposites based on modified $\mathrm{H}$ - $\mathrm{T}$ model with the random filler orientation according to Equation (16), as shown in Figure 3(b). The predicted elastic moduli of bionanocomposites were in fairly close agreement with experimental data. The percentage errors for modified
$\mathrm{H}-\mathrm{T}$ model with the random filler orientation were in the range of $0.7-7.6 \%$. On the other hand, for those models with MRF, the percentage errors were found to be between 0.9 and $2.5 \%$. Detailed percentage errors of each theoretical model are summarised in Table 3. Consequently, the prediction of elastic modulus by $\mathrm{H}-\mathrm{T}$ laminate model and modified $\mathrm{H}-\mathrm{T}$ random model with MRF appeared to be much closer to experimental data when compared with those without MRF.

Additionally, as seen in Figure 4, elastic moduli of bionanocomposites were also predicted by $\mathrm{H}-\mathrm{S}$ laminate model in terms of aspect ratio of clay fillers and clay content. Similarly, with the implementation of $\mathrm{H}$-T model and modified $\mathrm{H}-\mathrm{T}$ model, theoretically predicted elastic moduli of bionanocomposites exhibited different aspect ratios with increasing clay content. The increase in clay content revealed the reduction of aspect ratios for clay fillers in bionanocomposites. Nonetheless, the percentage errors between theoretical results and experimental data were ranging between 0.07 and $3.5 \%$, indicating excellent consistency with experimental data. It is implied that H-S laminate model offers better theoretical prediction for elastic moduli of bionanocomposites as opposed to other theoretical models used such as ROM model, Hirsch model, H-T laminate model and modified $\mathrm{H}-\mathrm{T}$ random model.

Clay aspect ratios presented special geometric characteristics of clay fillers in bionanocomposites. When clay platelet layers are dispersed well in matrices with the existence of single platelet layers, it leads to exfoliated structures with an aspect ratio as high as 1000 [77]. However, with respect to undispersed clay fillers in matrices, their aspect ratios can be significantly reduced to approximately 10 or even less. The theoretical prediction of elastic modulus by $\mathrm{H}-\mathrm{T}$ model and $\mathrm{H}-\mathrm{S}$ model could obtain estimated aspect ratios of clay fillers in bionanocomposite systems at different clay contents, as shown in Table 4. It was found that at a lower clay content of $1 \mathrm{wt} \%$, the effective aspect ratio reached the highest value in the range of 30 to 60 despite being still lower than that of single clay platelet at 100-1000. When the clay content increased up to 3 and $5 \mathrm{wt} \%$, effective aspect ratios decreased to a range of $15-30$ and 10-15, respectively. In addition, experiment data at the highest clay content of $8 \mathrm{wt} \%$ revealed the lowest aspect ratio $(\alpha \leq 5)$, possibly implying poor clay dispersion in nanocomposites. In relation to effective aspect ratios of clay particles, it was revealed that a closer aspect ratio prediction at clay contents of 3-8 wt\% was manifested in $\mathrm{H}-\mathrm{T}$ laminate model and modified $\mathrm{H}-\mathrm{T}$ random model with MRF. Similarly, a better aspect ratio prediction was also detected in both H-T models without MRF at the same clay contents. However, at the lower clay content of $1 \mathrm{wt} \%$, various aspect ratios were estimated for different $\mathrm{H}-\mathrm{T}$ models, which could be attributed to different assumptions used for determining geometric parameters to predict elastic moduli of nanocomposites using $\mathrm{H}$-T laminate model and modified $\mathrm{H}-\mathrm{T}$ random model.

On the other hand, H-S laminated model exhibited a higher aspect ratio prediction with more sensitivity when compared with various H-T models according to Table 4. Despite various aspect ratios, the prediction of effective 


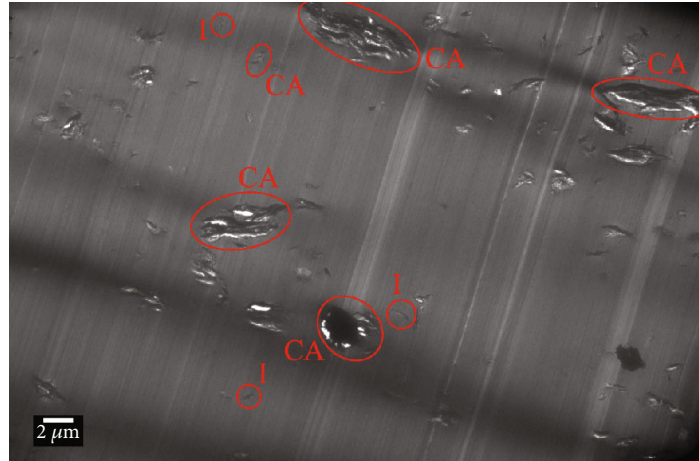

(a)

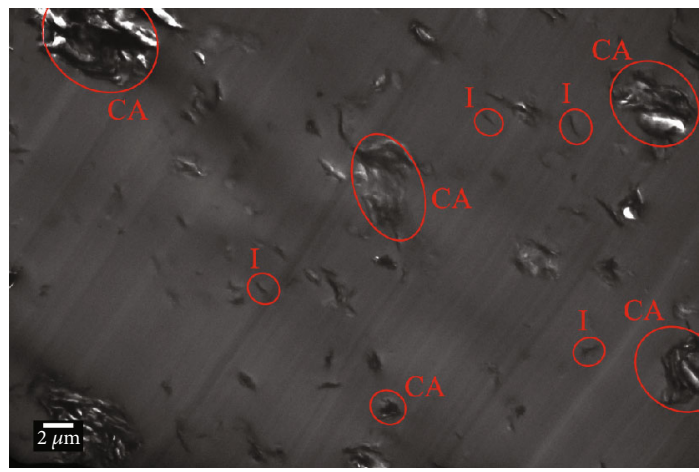

(c)

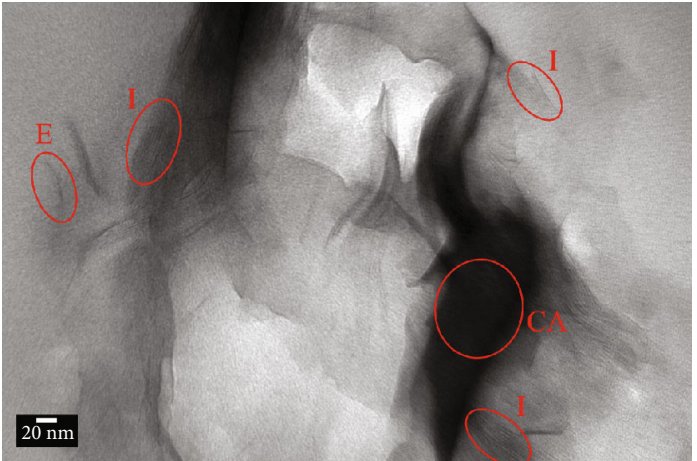

(b)

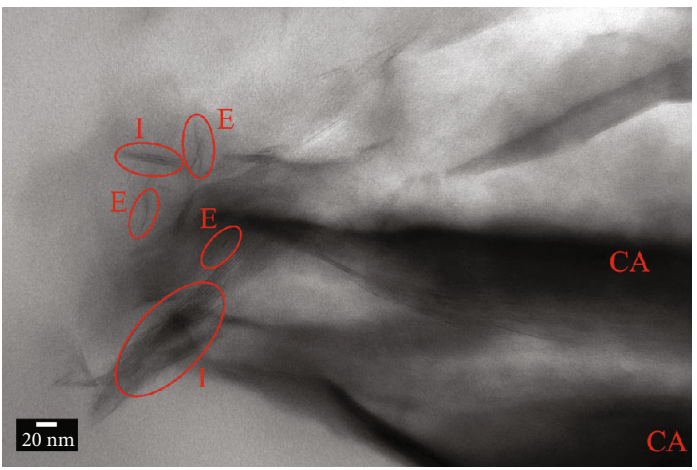

(d)

FIGURE 1: Typical TEM micrographs of bionanocomposites cured by IPDA (fixed ESO content: $20 \mathrm{wt} \%$ ) at different clay contents: (a) $5 \mathrm{wt} \%$ at $500 \mathrm{x}$ and (b) at 30,000x as well as (c) $8 \mathrm{wt} \%$ at 500x and (d) at 30,000x. The letters CA, I, and E represent clay aggregates, intercalated, and exfoliated structures, respectively.

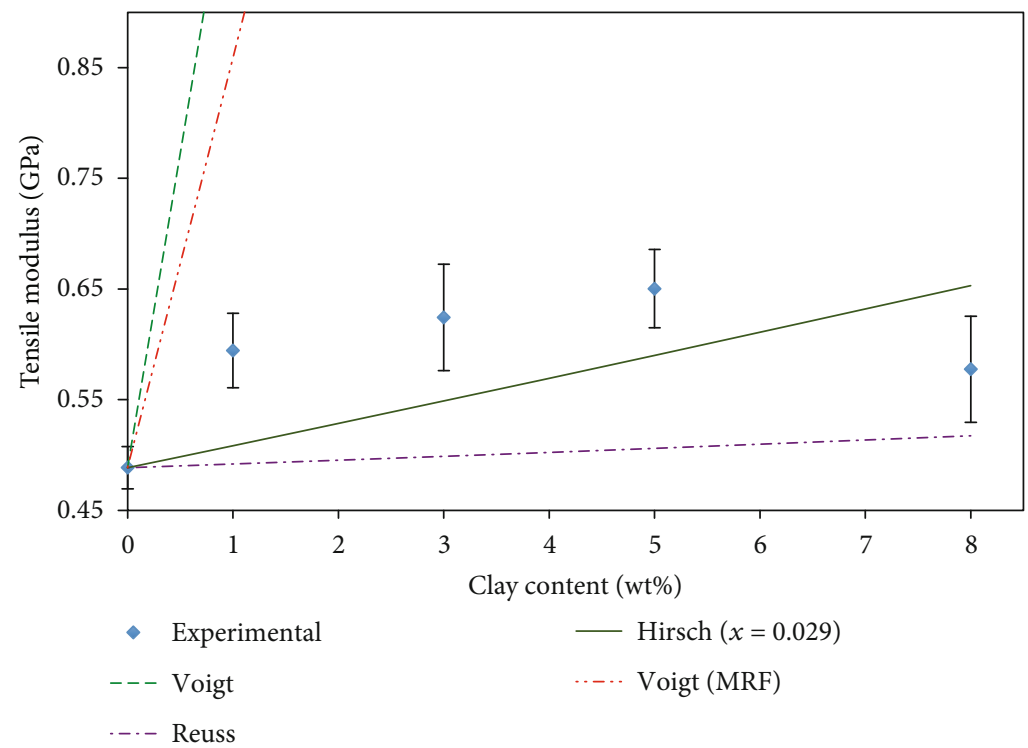

FIgURe 2: Comparison between theoretical prediction and experimental data for elastic moduli of bionanocomposites as a function of clay content.

aspect ratios is consistent with morphological structures of bionanocomposites depicted in Figure 1, which is evident in the presence of the random orientation of clay fillers in matrices and the increasing level of clay aggregation with increasing the clay content. More interestingly, elastic modulus predictions obtained using $\mathrm{H}$-S laminate model were closer to experimental data as opposed to those obtained from H-T models, especially at clay contents of $5-8 \mathrm{wt} \%$ 


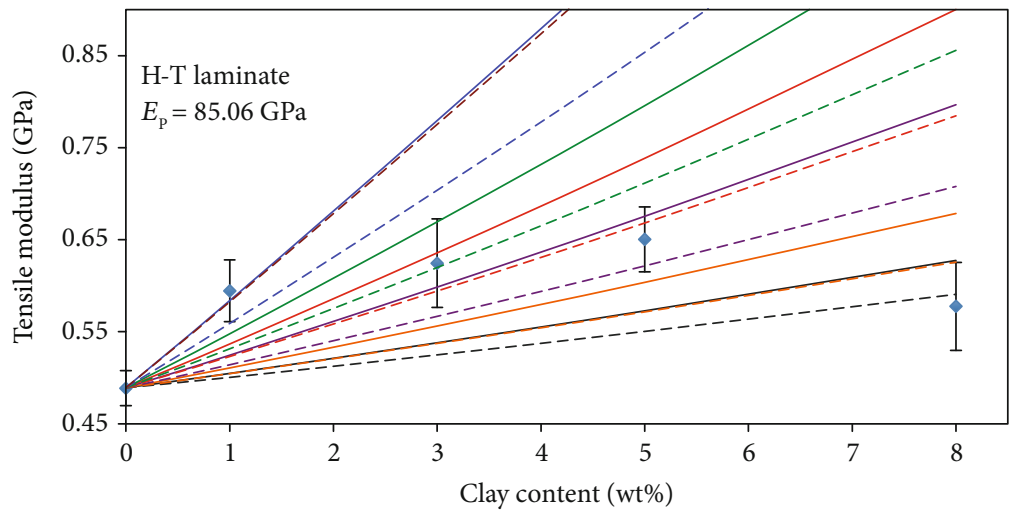

$$
\begin{aligned}
& \text { - Experimental } \quad \ldots-\alpha=3(\mathrm{MRF}) \\
& -\alpha=10 \quad--\alpha=15 \text { (MRF) }
\end{aligned}
$$

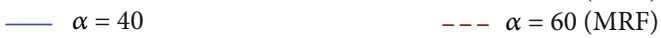

$$
\begin{aligned}
& --\alpha=10 \text { (MRF) } \quad-\alpha=5 \\
& --\alpha=40 \text { (MRF) } \quad-\alpha=20 \\
& -\alpha=3 \\
& -\alpha=15 \\
& \begin{aligned}
-\alpha & =20 \\
--\alpha & =5(\mathrm{MRF})
\end{aligned} \\
& ---\alpha=20(\mathrm{MRF})
\end{aligned}
$$

(a)

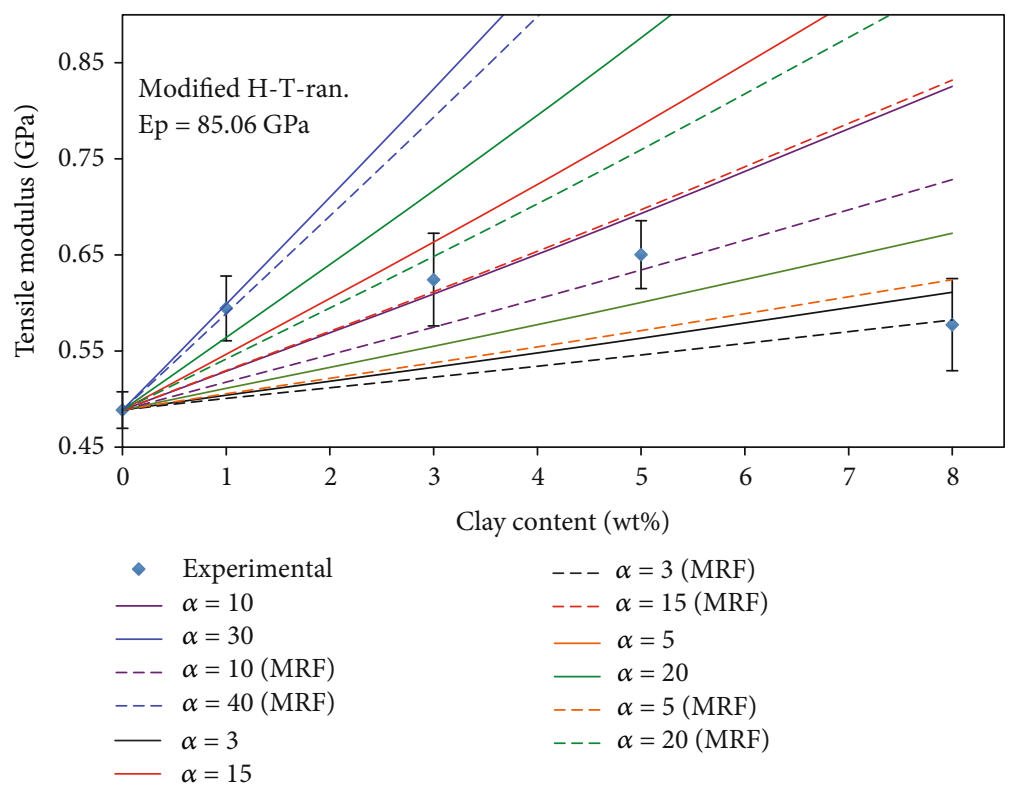

(b)

FIGURE 3: Theoretical prediction curves for elastic moduli of bionanocomposites with intercalated and randomly oriented clay fillers: (a) $\mathrm{H}$ - $\mathrm{T}$ laminate model and (b) modified $\mathrm{H}-\mathrm{T}$ model with random filler orientation.

shown in Table 3. The percentage errors of elastic modulus prediction for bionanocomposites at clay contents of 5 and $8 \mathrm{wt} \%$ by using $\mathrm{H}-\mathrm{S}$ laminate model were found to be approximately 1.84 and $0.07 \%$, respectively. Nonetheless, those predicted by modified $\mathrm{H}-\mathrm{T}$ random model were about 2.46 and $0.85 \%$ accordingly. In contrast, at lower clay contents of 1 and $3 \mathrm{wt} \%$, the percentage errors in elastic modulus prediction by $\mathrm{H}-\mathrm{S}$ laminate model were higher than those using $\mathrm{H}-\mathrm{T}$ models (i.e., approximately 1.6 and $3.48 \%$, respectively). As such, it is implied that $\mathrm{H}-\mathrm{S}$ laminate random model is more applicable to predict elastic moduli of bionanocomposites beyond the clay content of $5 \mathrm{wt} \%$. On the other hand, H-T laminate model and mod- ified H-T random model with/without MRF were confirmed to be more feasible for nanocomposites at the clay content below $3 \mathrm{wt} \%$.

3.1.2. Effect of ESO Content. Similar to the effect of clay content, theoretical predictions to elastic moduli of bionanocomposites were compared with experimental data using Equations (1) to (29). The estimated results of those predictions were depicted in Figures 5-8. At different ESO contents from 0 to $60 \mathrm{wt} \%$, elastic moduli of bioepoxy blends varied according to the ESO content, as shown in Table 5. In a similar manner, the densities of blend matrices were also altered based on different ESO contents. Additionally, the dispersion 


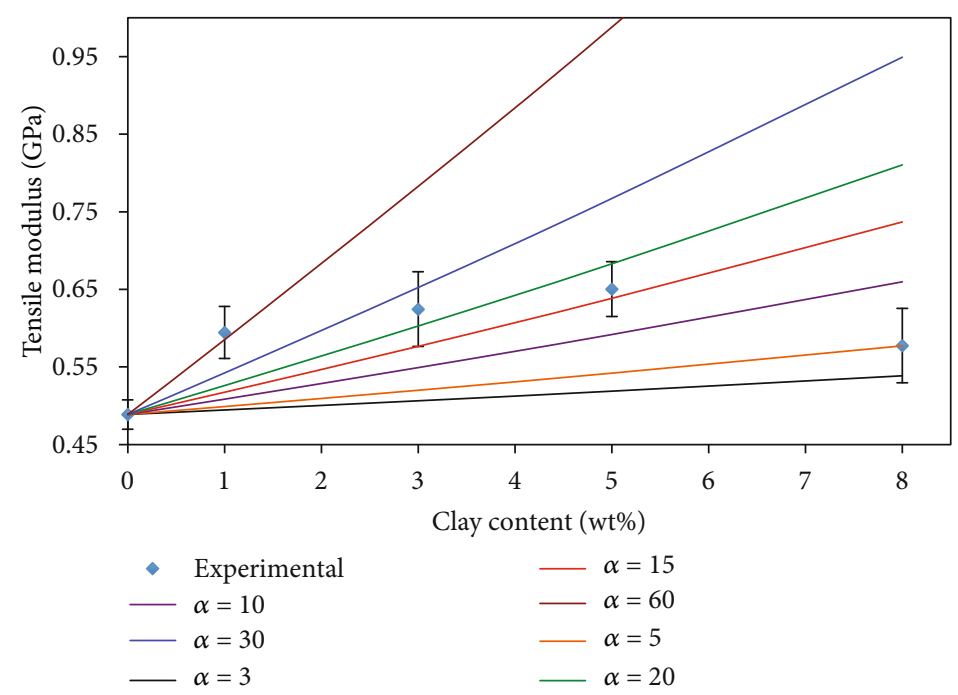

Figure 4: Comparison between theoretical modelling results and experimental data based on H-S laminate model at different filler aspect ratios.

TABle 3: Percentage errors in theoretical models in comparison with experimental data at different clay contents in bionanocomposites.

\begin{tabular}{lcccc}
\hline Theoretical model & \multicolumn{4}{c}{ Percentage error (\%) } \\
Clay content (wt\%) & 1 & 3 & 5 & 8 \\
\hline Voigt & 79.54 & 259.82 & 428.63 & 809.72 \\
Voigt (MRF) & 46.25 & 163.54 & 273.55 & 527.57 \\
Reuss & -17.25 & -20.11 & -22.19 & -10.41 \\
Hirsch & -14.47 & -12.09 & -9.27 & 13.10 \\
H-T laminate random & 2.75 & 1.95 & 3.27 & 8.66 \\
H-T laminate random with MRF & -1.98 & -0.74 & 2.73 & 2.28 \\
Modified H-T random & 0.71 & -2.40 & 6.59 & 5.85 \\
Modified H-T random with MRF & -0.91 & -2.03 & -2.46 & 0.85 \\
H-S laminate & -1.60 & -3.48 & -1.84 & -0.07 \\
\hline
\end{tabular}

Note: Negative values in percentage errors represent lower prediction values than experimental data.

status of clay fillers in nanocomposites affected elastic moduli of bionanocomposites. Hence, elastic moduli of clay particles were calculated based on Equation (6) along with the results listed in Table 5. Such elastic moduli of clay particles were calculated with the assumption that intercalated clay structures were dominantly formed as compared to other dispersion statuses (i.e., exfoliated and aggregated clay structures), which were based on XRD analysis results in the previous work [56] along with other parameters used for theoretical models in Table 5 . The clay content of $5 \mathrm{wt} \%$ in nanocomposites was fixed when using all different ESO contents in bionanocomposites.

In Figure 5, elastic moduli of nanocomposites show a declining trend with increasing the ESO content. As previously mentioned, the decrease in elastic modulus could result from the ESO plasticisation effect [56]. Increasing the ESO content yielded bionanocomposites with more rubber-like behaviour and less brittle nature in material properties. Voigt
TABLE 4: Aspect ratios of clay fillers based on curve fitting between experimental data and theoretical modelling results in bionanocomposites.

\begin{tabular}{lcccc}
\hline Theoretical model & \multicolumn{4}{c}{ Aspect ratio } \\
Clay content (wt\%) & 1 & 3 & 5 & 8 \\
\hline H-T laminate & $\sim 40$ & $10-15$ & $5-10$ & $<3$ \\
H-T laminate with MRF & $\sim 60$ & $\sim 20$ & $10-15$ & $<3$ \\
Modified H-T random & $\sim 30$ & $10-15$ & $5-10$ & $<3$ \\
Modified H-T random with MRF & $\sim 40$ & $15-20$ & $10-15$ & $\sim 3$ \\
H-S laminate & $\sim 60$ & $20-30$ & $\sim 15$ & $\sim 5$ \\
\hline
\end{tabular}

model and the Reuss model could only provide rough predictions for the elastic moduli of bionanocomposites at different ESO contents, as depicted in Figure 5. It was seen that theoretical prediction of Reuss model being the lower bound gave better estimation than Voigt model as the upper bound. This result suggested that series model for filler-matrix interaction became more dominant as compared with parallel model. Moreover, since clay fillers in matrices appeared to be more randomly distributed, the combination of series and parallel models could also apply in predicting elastic moduli of nanocomposites by using Hirsch model. The curve fitting with experimental data revealed the controlling factor $x$ was determined to be about 0.006 for clay nanocomposites with parallel orientation. Considering the value of $x$ in the range between 0 and $1, x$ for series model was finally found to be 0.994 . It was suggested that series model for fibre-matrix interaction became more dominant in good accordance with Reuss model mentioned earlier.

On the other hand, calculated percentage errors for each theoretical model were listed in Table 6, which were obtained from the percentage of the difference between experimental data and theoretical modelling results. As clearly seen, theoretical predictions using Reuss model and Hirsch model 


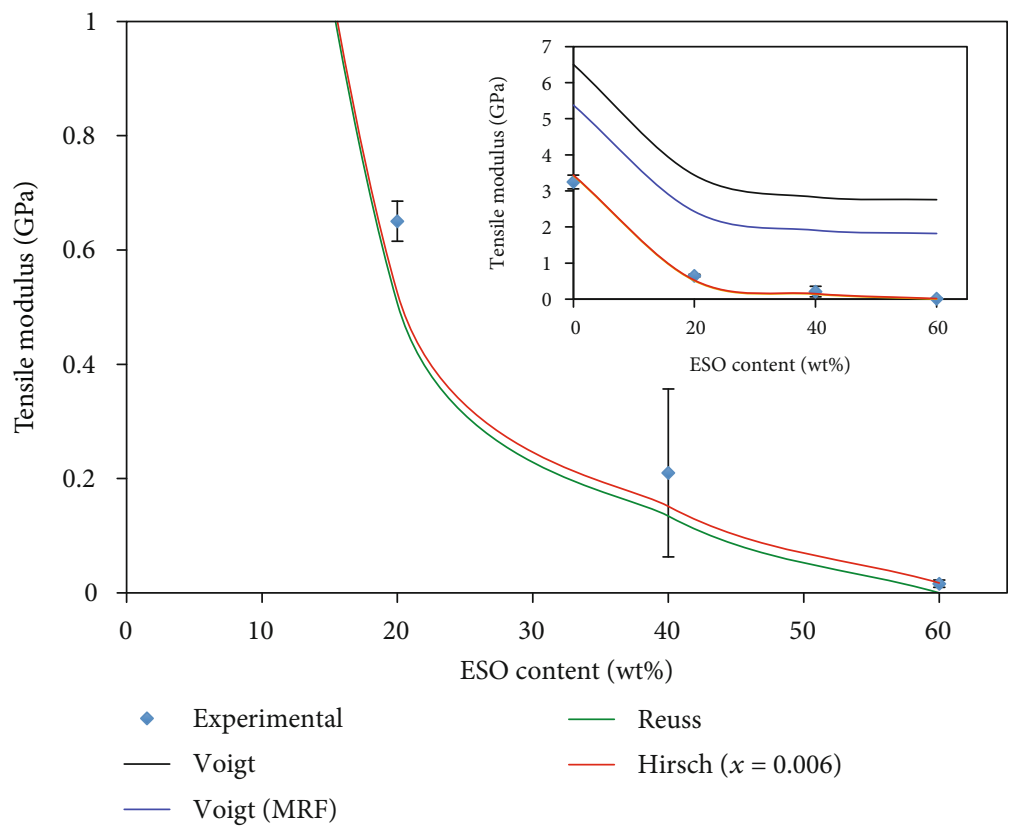

FIGURE 5: Comparison between theoretical modelling results and experimental data for elastic moduli of bionanocomposites as a function of ESO content.

became much closer to experimental data as compared with Voigt model and Voigt (MRF) model. For instance, without ESO (i.e., $0 \mathrm{wt} \%$ ESO), comparable percentage errors of approximately 5.30 and $5.89 \%$ in Reuss model and Hirsch model were reported, respectively, as opposed to Voigt model with about $100 \%$ in percentage error. More interestingly, theoretical predictions of elastic moduli of bionanocomposites with the addition of $60 \mathrm{wt} \%$ ESO were shown to be in good agreement with experimental data using Hirsch model. The percentage error of proposed Hirsch model at the ESO content of $60 \mathrm{wt} \%$ was approximately $7 \%$, which was the closest prediction when compared with other proposed theoretical models listed in Table 6.

With respect to the random orientation of clay fillers in matrices, 3D laminate model was employed to predict elastic moduli of bionanocomposites at different ESO contents, along with $\mathrm{H}-\mathrm{T}$ model and $\mathrm{H}-\mathrm{S}$ model according to Equations (14) to (29). Nonetheless, since it was found that clay structures were the combination of partial intercalation/exfoliation and particle aggregation, the MRF of 0.66 was used in $\mathrm{H}$-T model equations. The associated curves showing the elastic modulus prediction by $\mathrm{H}-\mathrm{T}$ laminate model and modified $\mathrm{H}-\mathrm{T}$ random model with MRF were depicted in Figures 6 and 7. H-T laminate model with MRF in Figure 6 was in good accordance with experimental data of bionanocomposites especially at the ESO contents of 20 and $40 \mathrm{wt} \%$, leading to a small percentage error at approximately 2.73 and $5.24 \%$, respectively. In addition, at the ESO content of $0 \mathrm{wt} \%$, the theoretical prediction appeared to overestimate experimental data as opposed to their underestimation at a higher ESO content of $60 \mathrm{wt} \%$. The overestimated values could be attributed to geometric constants involved in the equations, as detected from the theoretical prediction of Reuss model and Hirsch model $(x=0.006)$. Those findings suggested dominantly transverse orientation of clay structures in conventional epoxy matrices.

On the other hand, modified $\mathrm{H}-\mathrm{T}$ random model according to Equation (16) and modified $\mathrm{H}$-T random model with MRF based on Equation (21) are demonstrated in Figure 7. It was seen that the modification of $\mathrm{H}$-T model affected the prediction of filler aspect ratios, especially at the ESO contents of 20 and $40 \mathrm{wt} \%$, even though the percentage errors in modified $\mathrm{H}-\mathrm{T}$ random model with MRF were comparable to those in H-T laminate model with MRF shown in Table 6. Additionally, it was found that filler aspect ratios of nanocomposites varied according to different ESO contents exhibited in Figure 7. Nonetheless, the use of MRF showed an increasing aspect ratio as compared with that without MRF. The aspect ratios of conventional nanocomposites (i.e., $0 \mathrm{wt} \% \mathrm{ESO}$ ) exhibited comparable values when predicted using $\mathrm{H}$ - $\mathrm{T}$ laminate model and modified $\mathrm{H}$ - $\mathrm{T}$ random model with MRF resulting in aspect ratios of fillers less than 3. This could suggest that clay fillers were undispersed in conventional epoxy, which was likely to form aggregated clay fillers in matrices. However, a further increase in ESO content revealed increasing aspect ratio values. At the ESO content of $20 \mathrm{wt} \%$, the aspect ratio predicted by $\mathrm{H}-\mathrm{T}$ laminate model with MRF was improved in range of 5-10. Whereas, the additional ESO at approximately $40 \mathrm{wt} \%$ yielded the aspect ratios of 10-15. In addition, with respect to modified H-T random model with MRF, its predicted aspect ratios of bionanocomposites at 20 and $40 \mathrm{wt} \%$ were slightly higher than those based on $\mathrm{H}-\mathrm{T}$ laminate model with MRF, leading to aspect ratios of 10-15 and approximately 20, respectively. Finally, bionanocomposites with $60 \mathrm{wt} \%$ ESO exhibited an aspect ratio over 20 for both $\mathrm{H}-\mathrm{T}$ model and modified H-T model. Nonetheless, the percentage errors in each H-T model were observed to be similar, 


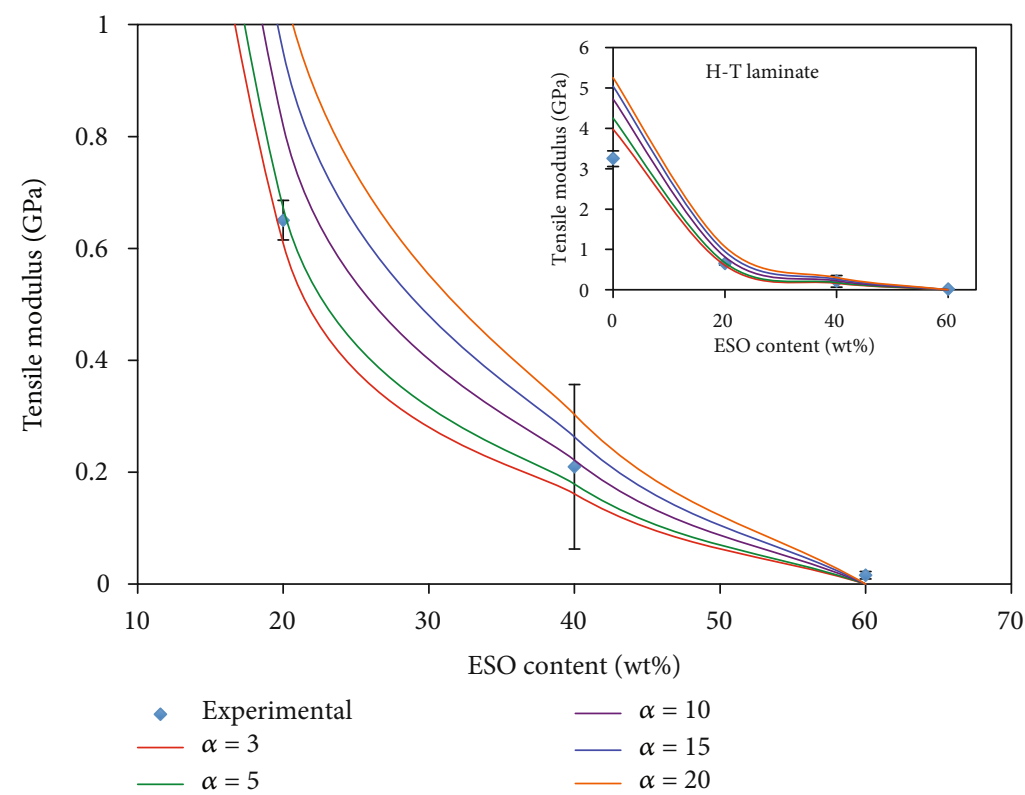

(a)

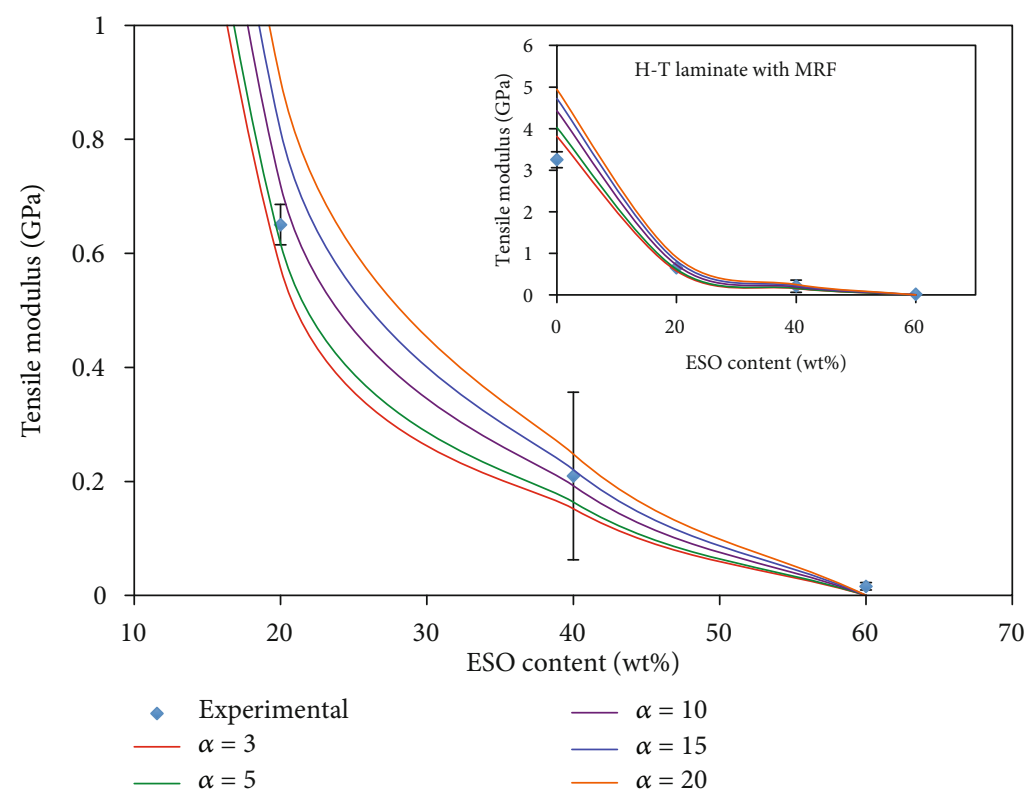

(b)

FIGURE 6: Comparison between theoretical modelling results and experimental data for elastic moduli of bionanocomposites using different aspect ratios calculated based on (a) H-T laminate model and (b) H-T laminate model with MRF.

which were found to be $\sim 99 \%$ less than those obtained from corresponding experimental data. This unpredicted elastic modulus could be attributed to particle-size effect in relation to filler aspect ratios, as well as particle content [54, 78]. Since aspect ratio values represented particle sizes of clays dispersed in bioepoxy matrices, the reduction in clay particle sizes would increase the aspect ratios of clay fillers. Similarly, with the effect of filler inclusion, the increase in the filler aspect ratio would decrease the size of dispersed clay fillers in matrices as expected, which might further improve the rigidity of nanocomposites. More interestingly, the high elastic modulus of bionanocomposites at $85.08 \mathrm{GPa}$ in experimental data with $60 \mathrm{wt} \%$ ESO was likely to be associated with a far higher modulus of clay particles as opposed to that of corresponding bioepoxy (i.e., $10^{-4} \mathrm{GPa}$ ). The high elastic modulus of clay fillers could improve the stiffness of bionanocomposites. A direct effect arising from the clay inclusion into rubber-like bioepoxy matrices would significantly influence the deformation reduction of bionanocomposites as opposed to that of neat bioepoxy at high ESO contents.

In addition to the effect of aspect ratio and modulus of fillers, the orientation of dispersed clay fillers also significantly affected elastic modulus, which was indicative of the 


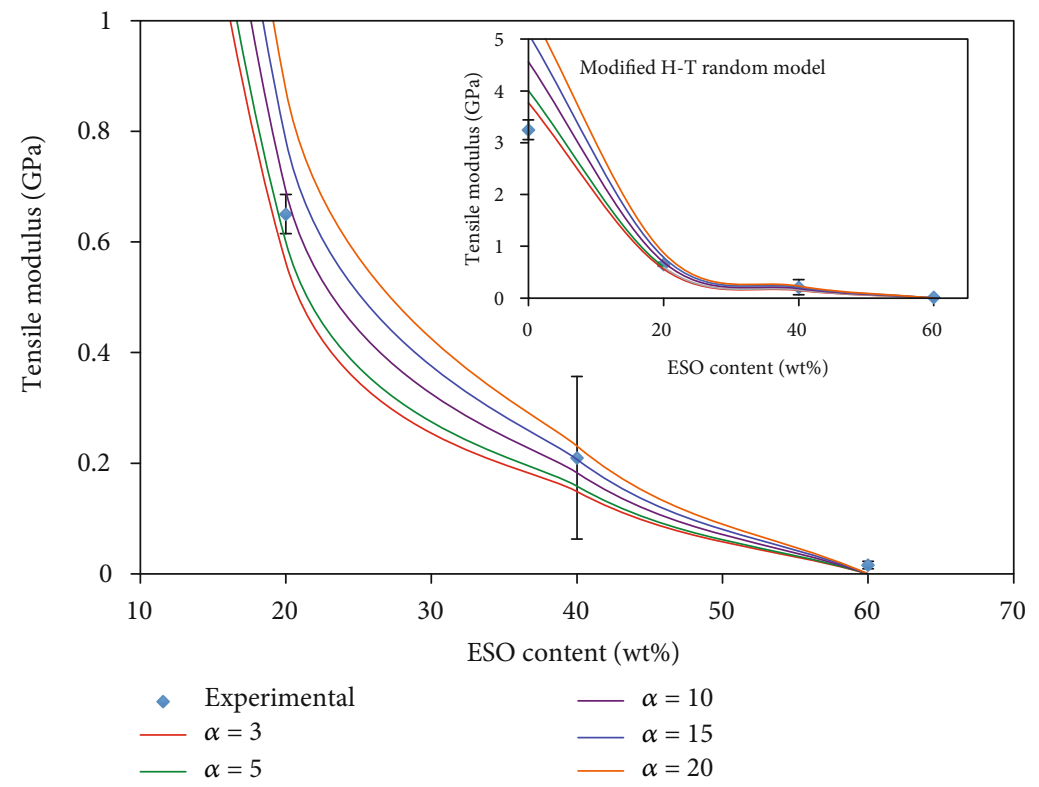

(a)

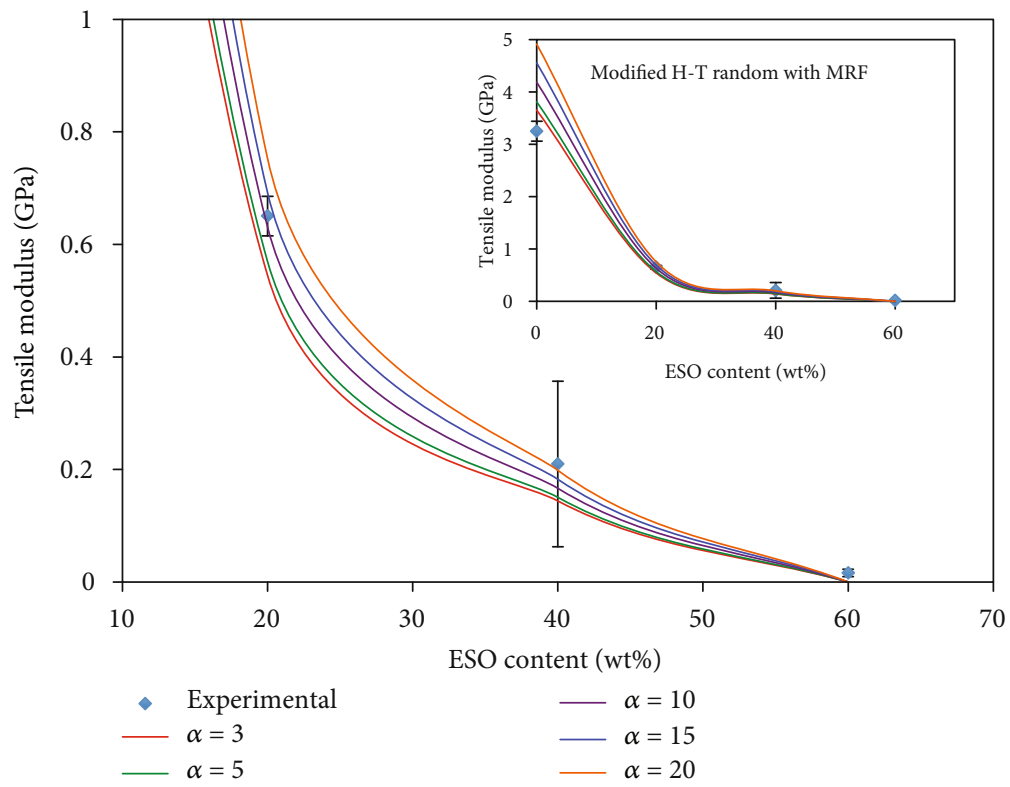

(b)

FIGURE 7: Comparison between theoretical modelling results and experimental data for elastic moduli of bionanocomposites at different aspect ratios calculated based on (a) modified $\mathrm{H}-\mathrm{T}$ random model and (b) modified $\mathrm{H}-\mathrm{T}$ random model with MRF.

percentage of the difference between theoretical prediction calculated according to Equation (29) for H-T laminate random model and Equation (16) for modified $\mathrm{H}-\mathrm{T}$ random model and experimental data. From an experimental point of view, modified $\mathrm{H}$-T random model with lower percentage errors is more applicable to predict elastic moduli of bionanocomposites when compared with $\mathrm{H}-\mathrm{T}$ laminate random model. This can be associated with different interpretations in determining the constant values of $\left(E_{11}\right)$, which are 0.375 and $0.49 \mathrm{GPa}$ for modified $\mathrm{H}$-T random model and $\mathrm{H}$ - $\mathrm{T}$ laminate model, respectively. Furthermore, it is very critical to predict filler aspect ratios in matrices based on the theoretical prediction of elastic moduli of nanocomposites with the combination of random orientation of fillers in the matrices.

On the other hand, with respect to H-S laminate model, the theoretical prediction of bionanocomposites in comparison with experimental data was shown in Figure 8. Clearly, the curve fitting by H-S laminate model demonstrated good prediction for filler aspect ratios in experiment data. The aspect ratios predicted by $\mathrm{H}-\mathrm{S}$ laminate model were summarised in Table 7 . Increasing the ESO content dramatically enhanced the aspect ratios of clay fillers in bionanocomposites. Conventional nanocomposites (i.e., $0 \mathrm{wt} \%$ ESO) presented the lowest aspect ratios below 3 . The aspect ratios of 


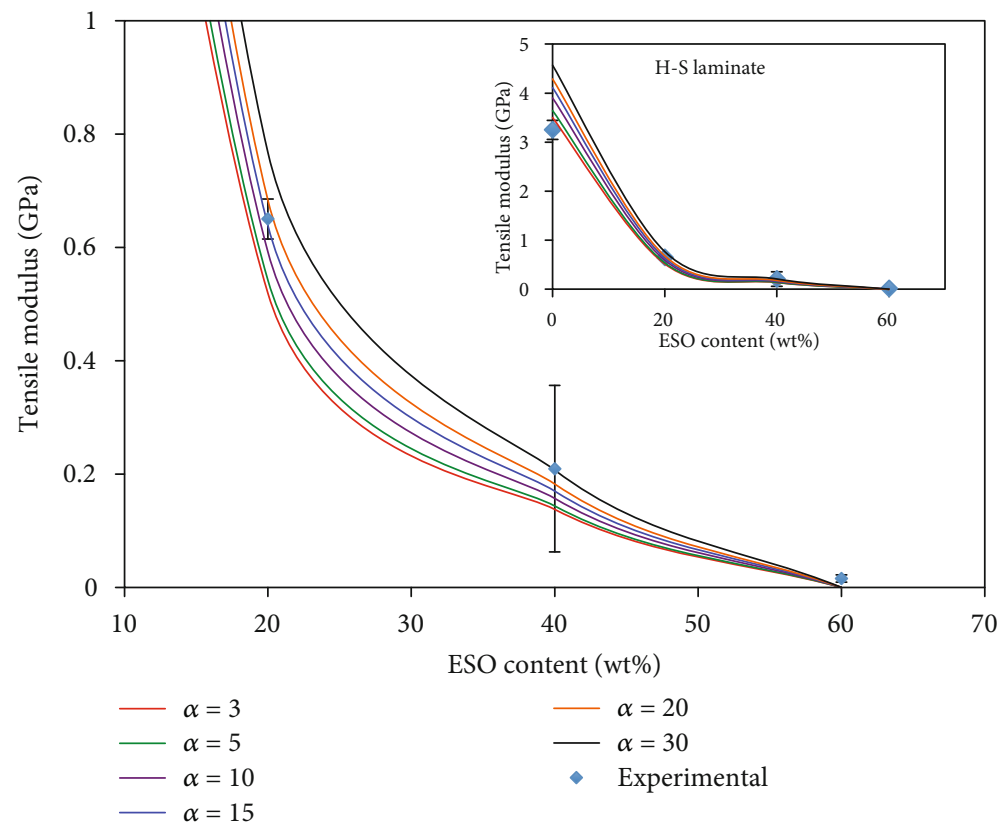

FIGURE 8: Elastic modulus predictions of bionanocomposites reinforced with $5 \mathrm{wt} \%$ clays as a function of ESO content at different filler aspect ratios using H-S laminate model.

TABLE 5: Tensile properties of blend matrices and effective moduli of intercalated clay particles in bionanocomposites (fixed clay content: $5 \mathrm{wt} \%)$.

\begin{tabular}{|c|c|c|c|c|c|}
\hline \multirow{2}{*}{$\begin{array}{l}\text { ESO } \\
\text { content } \\
\text { (wt } \%)\end{array}$} & \multirow{2}{*}{$\begin{array}{c}E_{\text {blend }} \\
\mathrm{GPa}\end{array}$} & \multirow{2}{*}{$\begin{array}{l}\sigma_{\text {blend }} \\
\mathrm{MPa}\end{array}$} & \multirow{2}{*}{$\begin{array}{l}\rho_{\text {blend }} \\
\mathrm{g} \cdot \mathrm{cm}^{-3}\end{array}$} & \multicolumn{2}{|c|}{$\begin{array}{l}\text { Bionanocomposites at a fixed } \\
\text { clay content of } 5 \mathrm{wt} \%\end{array}$} \\
\hline & & & & $\begin{array}{c}d_{002}[56] \\
(\mathrm{nm})\end{array}$ & $\begin{array}{l}E_{\text {intercalation }} \\
\quad(\mathrm{GPa})\end{array}$ \\
\hline 0 & 3.30 & 59.56 & 1.17 & 1.80 & 92.72 \\
\hline 20 & 0.49 & 28.53 & 1.13 & 1.96 & 85.59 \\
\hline 40 & 0.13 & 10.26 & 1.09 & 2.07 & 80.65 \\
\hline 60 & $1 \times 10^{-4}$ & 0.29 & 1.06 & 1.97 & 85.08 \\
\hline
\end{tabular}

bionanocomposites with $20 \mathrm{wt} \%$ ESO were in the range of 15 20 , as opposed to nearly 30 for bionanocomposites at the ESO content of $40 \mathrm{wt} \%$. When the ESO content was $60 \mathrm{wt} \%$, the predicted filler aspect ratio reached a level higher than 30, as illustrated in Figure 8. Additionally, the effect of clay content also revealed that the theoretical prediction of elastic moduli of bionanocomposites determined by H-S laminate model led to closer prediction values given in Table 6. The percentage errors for bionanocomposites up to $40 \mathrm{wt} \% \mathrm{ESO}$ were below 7\%, which appeared to be greater up to almost $100 \%$ at the ESO content of $60 \mathrm{wt} \%$. In contrast to other theoretical models, the application of H-S laminate model yielded much better elastic modulus prediction with lower percentage errors, especially for bionanocomposites at the ESO contents of 20 and $40 \mathrm{wt} \%$ (i.e., $~ 1.84$ and $1.16 \%$, respectively). Moreover, filler aspect ratios predicted by H-S laminate model remained at a high level as opposed to those estimated by other theoretical models. As a result, when the effect of ESO content on bionanocomposites reinforced by $5 \mathrm{wt} \%$ clays was investigated, it was evident that H-S laminate model appeared to be more reliable in predicting their elastic moduli against experimental data. This was especially the case for bionanocomposites at the ESO contents below $40 \mathrm{wt} \%$. On the other hand, when the ESO content was as high as $60 \mathrm{wt} \%$, Hirsch model with the combination of parallel and series orientations became more applicable in estimating elastic moduli of bionanocomposites.

\subsection{Tensile Strength of Nanocomposites}

3.2.1. Effect of Clay Fillers. The theoretical tensile strength values predicted by Equations (30)-(34) were compared with experimental data of bionanocomposites cured by IPDA at a fixed ESO content of $20 \mathrm{wt} \%$. Figure 9 showed the theoretical prediction of nanocomposites by using different theoretical models to fit experimental data. Tensile strengths of bionanocomposites demonstrated an initially enhancing trend when increasing the clay content from 1 to $5 \mathrm{wt} \%$ along with the further reduction at the higher clay content of $8 \mathrm{wt} \%$, as illustrated in Figure 9. Four different theoretical models were also employed to predict tensile strength values for bionanocomposites. N-N model and T-P-T model $(B=0)$ underestimated the experimental data in relation to tensile strengths of bionanocomposites, implying that bionanocomposites possessed better interfacial adhesion between clay fillers and matrices, thus resulting in an increase in tensile strength with the inclusion of clay fillers. The further analysis for experimental data of bionanocomposites was based on the adoption of D-T model and $\mathrm{Lu}$ model in comparison with experiment data. As shown in Figure 9, it was observed that a comparable correlation between theoretical modelling results and experimental data predicted by $\mathrm{D}-\mathrm{T}$ model was 
TABLE 6: Percentage errors in theoretical predictions in comparison with experimental data based on different theoretical models at various ESO contents in bionanocomposites.

\begin{tabular}{|c|c|c|c|c|}
\hline \multirow{2}{*}{$\begin{array}{l}\text { Theoretical model } \\
\text { ESO content (wt\%) }\end{array}$} & \multicolumn{4}{|c|}{ Percentage error $(\%)$} \\
\hline & 0 & 20 & 40 & 60 \\
\hline Voigt & 100.08 & 428.63 & 1249.97 & 17121.94 \\
\hline Voigt (MRF) & 65.38 & 273.55 & 811.35 & 11266.69 \\
\hline Reuss & 5.30 & -22.19 & -35.87 & -99.35 \\
\hline Hirsch & 5.89 & -9.27 & -27.91 & 7.20 \\
\hline H-T laminate & 22.48 & 3.27 & 5.64 & -98.52 \\
\hline H-T laminate with MRF & 17.39 & 2.73 & 5.24 & -98.80 \\
\hline Modified $\mathrm{H}-\mathrm{T}$ random & 16.04 & 6.59 & -1.20 & -98.90 \\
\hline Modified $\mathrm{H}-\mathrm{T}$ random with MRF & 12.38 & -2.46 & -5.35 & -99.06 \\
\hline H-S laminate random & 7.79 & -1.84 & -1.16 & -99.01 \\
\hline
\end{tabular}

Note: Negative values in percentage errors represent lower prediction values than experimental data.

TABLE 7: Aspect ratios of clay fillers based on curve fitting of experimental data with theoretical models at different ESO contents in bionanocomposites.

\begin{tabular}{lcccc}
\hline Theoretical model & \multicolumn{4}{c}{ Aspect ratio } \\
ESO content (wt\%) & 0 & 20 & 40 & 60 \\
\hline H-T laminate & $<3$ & $3-5$ & $\sim 10$ & $>20$ \\
H-T laminate with MRF & $<3$ & $5-10$ & $10-15$ & $>20$ \\
Modified H-T random & $<3$ & $5-10$ & $\sim 15$ & $>20$ \\
Modified H-T random with MRF & $<3$ & $10-15$ & $\sim 20$ & $>20$ \\
H-S laminate & $<3$ & $15-20$ & $\sim 30$ & $>30$ \\
\hline
\end{tabular}

achieved as opposed to Lu model at the high clay content of $8 \mathrm{wt} \%$.

On the other hand, T-P-T model was also employed to be compared with experimental data for bionanocomposites, and the curve fitting based on T-P-T model yielded $B=$ 4.718. It was suggested that bionanocomposites could benefit from the reinforcing effect by increasing the clay filler content along with better matrix-filler interfacial bonding when $B$ value is over 3 . Additionally, due to the high difference between theoretical prediction and experimental data in bionanocomposites at the clay content of $8 \mathrm{wt} \%$, the theoretical prediction obtained from T-P-T model was also used for experimental data at the clay contents from 1 to $5 \mathrm{wt} \%$ presented in Figure 9. It was determined that the empirical constant of $B=8.693$, which indicated that bionanocomposites at clay contents from 1 to $5 \mathrm{wt} \%$, exhibited better interfacial bonding resulting in more effective filler-matrix load transfer than that at $8 \mathrm{wt} \%$. In addition, bionanocomposites at the clay content of $8 \mathrm{wt} \%$ presented a lower tensile strength value as compared with that predicted by T-P-T model with $B=3$. Furthermore, those results suggested that such bionanocomposites at the clay content of $8 \mathrm{wt} \%$ might arise from the weak interfacial bonding between clay fillers and matrices without reinforcing effect [73-76]. Nonetheless, such a prediction had good agreement with SEM analysis results, as indicated in our previous study [56] where microcracks existed close to interfacial areas between clay fillers and matrices.
3.2.2. Effect of ESO Content. Similar to the effect of clay content, the prediction for tensile strengths of bionanocomposites at a fixed clay content of $5 \mathrm{wt} \%$ was compared with experimental data as a function of ESO content, Figure 10. It was clearly seen that experimental data for tensile strengths of bionanocomposites were reduced when increasing the ESO content from 20 to $60 \mathrm{wt} \%$ despite the strength improvement as opposed to that of neat matrices. In addition, tensile strengths of conventional nanocomposites (i.e., $0 \mathrm{wt} \% \mathrm{ESO}$ ) exhibited a declining tendency with the inclusion of $5 \mathrm{wt} \%$ clay fillers.

With respect to the theoretical prediction, as can be seen in Figure 10, all proposed models failed to present good predictions to fit all experimental data of tensile strengths. The percentage errors of proposed model prediction for tensile strength were enhanced with increasing the ESO content, as displayed in Table 8 . The proposed models could thus only fit one or two experimental data. From the hypothesis of particle-matrix interfacial interaction, $\mathrm{N}-\mathrm{N}$ model and T-P$\mathrm{T}$ (at $B=0$ ) model were in better accordance with experimental data for conventional nanocomposites (0 wt $\%$ ESO). Percentage errors in N-N model and T-P-T model $(B=0)$ exhibited comparable values of approximately 0.27 and $2.17 \%$, respectively, as opposed to experimental data (i.e., $0 \mathrm{wt} \% \mathrm{ESO})$. Since N-N model and T-P-T model $(B=0)$ were categorised as lower bounds for modelling tensile strength, it could be suggested that conventional nanocomposites (i.e., $0 \mathrm{wt} \% \mathrm{ESO}$ ) had poor filler-matrix interfacial bonding. However, other theoretical models such as D-T model and $\mathrm{Lu}$ model presented an overestimation of tensile strengths in contrast with experimental data. The percentage error was found to be over $10 \%$ for those two models according to Table 8 .

On the other hand, with respect to T-P-T model, the curve fitting with experimental data offered an empirical constant $B=1.273$. However, the prediction curve failed to fit well with the experimental data at the ESO contents from 0 to $60 \mathrm{wt} \%$. Furthermore, in the further analysis, experimental data were only used from 20 to $60 \mathrm{wt} \%$ in the subsequent model prediction as bionanocomposites with $0 \mathrm{wt} \%$ ESO presented a comparable prediction using T-P-T model with an empirical constant $B=0$. Further prediction calculations 


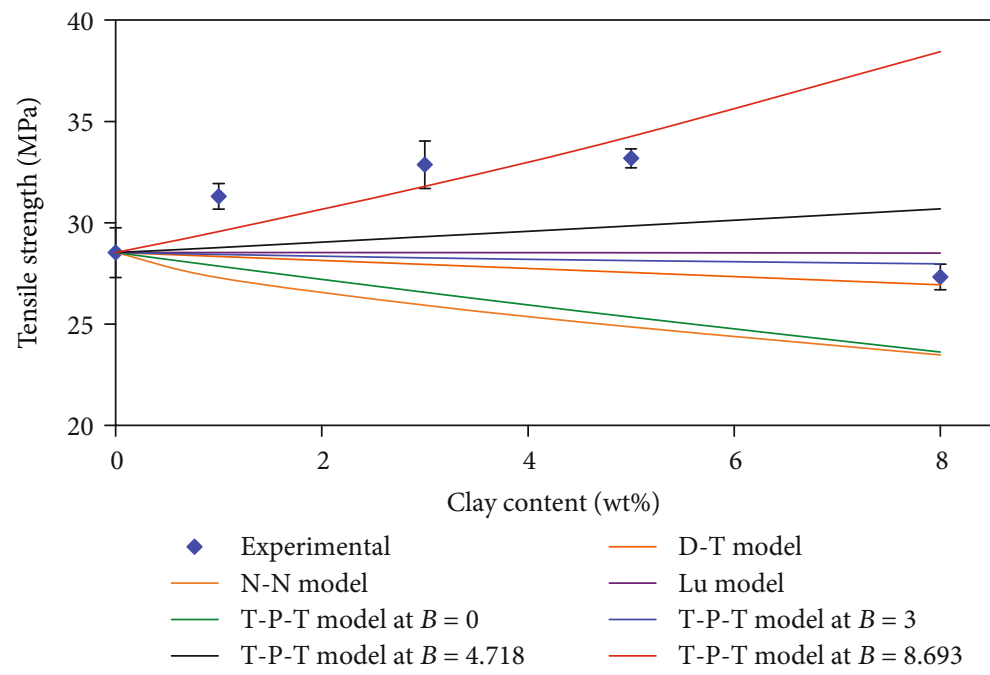

Figure 9: Comparison between theoretical modelling results and experimental data of tensile strengths of bionanocomposites at different clay contents.

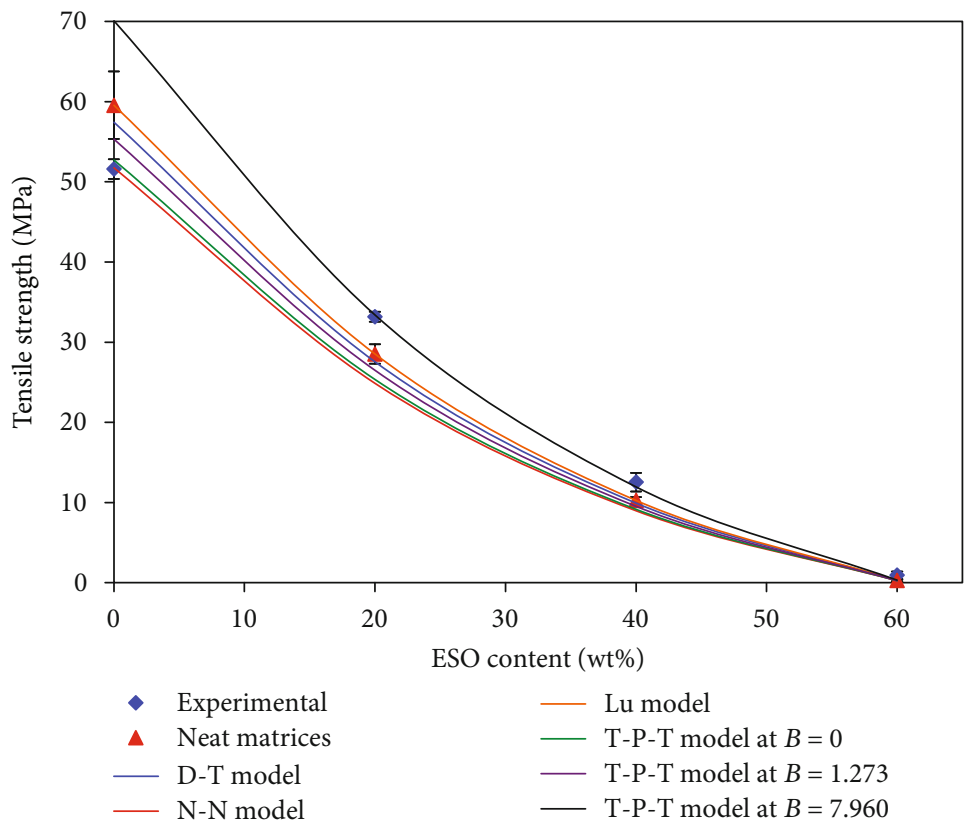

Figure 10: Tensile strength predictions of bionanocomposites reinforced with fixed $5 \mathrm{wt} \%$ clays as a function of ESO content using different theoretical models.

based on three proposed experimental data were shown in Figure 10. The curve fitting with experimental data (20 to $60 \mathrm{wt} \% \mathrm{ESO})$ revealed better agreement with T-P-T model results along with the resulting value of $B=7.960$. From this prediction using T-P-T model $(B=7.960)$, the percentage differences between experimental data and theoretical prediction were 0.67 and $4.63 \%$ for tensile strengths of bionanocomposites with the inclusions of 20 and $40 \mathrm{wt} \% \mathrm{ESO}$, respectively. Moreover, T-P-T model $(B=7.960)$ revealed a closer correlation with experimental data as opposed to other proposed strength prediction models according to the percentage errors listed in Table 8.
On the other hand, prediction models for tensile strengths of bionanocomposites with $60 \mathrm{wt} \%$ ESO presented a high percentage of the difference when compared with experimental data (Table 8). As such, it was suggested that the high improvement in tensile strength of bionanocomposites (i.e., $60 \mathrm{wt} \% \mathrm{ESO}$ ) could be attributed to structural factors due to different morphological structures and interfacial bonding interaction between fillers and matrices. Turcsányi et al. [73] has noted that structural factors, which could influence stress concentration, are the shape and the size of dispersed fillers, spatial distribution of matrices, and interface thickness. In practice, as previously mentioned in 
TABLE 8: Percentage errors for proposed tensile strength predictions in bionanocomposites at different ESO contents.

\begin{tabular}{lcccc}
\hline Theoretical model & \multicolumn{4}{c}{ Percentage error (\%) } \\
ESO content (wt\%) & 0 & 20 & 40 & 60 \\
\hline D-T model & 11.31 & -16.98 & -20.87 & -70.02 \\
N-N model & 0.27 & -25.07 & -28.43 & -72.83 \\
Lu model & 15.38 & -14.04 & -18.16 & -69.03 \\
T-P-T model $(B=0)$ & 2.17 & -23.60 & -26.98 & -72.46 \\
T-P-T model $(B=1.273)$ & 7.21 & -20.13 & -23.95 & -71.42 \\
T-P-T model $(B=7.960)$ & 35.83 & 0.67 & -4.63 & -64.34 \\
\hline
\end{tabular}

Note: Negative values in percentage errors represent lower prediction values than experimental data.

the theoretical predictions of elastic moduli of bionanocomposites, increasing the ESO content yielded higher aspect ratios of clay fillers in matrices. Furthermore, the improvement of aspect ratios can also be associated with the reduction of filler size in matrices, resulting in a much higher increase in clay surface areas. As such, high clay surface areas could cause better matrix-filler interaction, which offered positive impact on the strength improvement with more efficient stress transfer from fillers to matrices.

\section{Conclusions}

A comparison between experimental data and theoretical predictions with respect to tensile properties of bioepoxy/clay nanocomposites has been demonstrated successfully. Most proposed theoretical models for tensile modulus predictions revealed good agreement with experimental data except Voigt model and Reuss model. Hirsch model with the combination of series and parallel filler orientations revealed reasonable prediction for constant parameter $x$ where $x=0.029$ in the parallel direction. Among various models, $\mathrm{H}$-T laminate model and modified $\mathrm{H}$-T random model with MRF, as well as H-S laminate model, revealed very good correlation with experimental data when the percentage errors appeared to be below 3.5\%. Nonetheless, it was also clearly noted that aspect ratios of clay fillers in bionanocomposites decreased with increasing the clay filler content.

Theoretical predictions of tensile modulus as a function of ESO content demonstrated partial correlation with experimental data for most proposed models except Voigt model. Similar to the effect of clay content, Voigt model overestimated experimental data owing to the assumption of filler alignment in the longitudinal direction. In case of conventional nanocomposites (i.e., $0 \mathrm{wt} \% \mathrm{ESO}$ ), lower-bound model predictions (i.e., Reuss model and Hirsch model with $x=$ $0.006)$ and H-S laminate model fitted well with experimental data (error percentage $<10 \%$ ). However, at the ESO contents of $20-40 \mathrm{wt} \%$, H-T laminate model, modified $\mathrm{H}-\mathrm{T}$ random model, and $\mathrm{H}-\mathrm{S}$ laminate model demonstrated very good agreement with experimental data resulting in the percentage errors being less than $5 \%$. In addition, as for bionanocomposites with $60 \mathrm{wt} \%$ ESO, most proposed theoretical models underestimated experimental data except Hirsch model. A good agreement between experimental data and Hirsch model was observed when $x=0.006$ in the parallel filler orientation. This suggested that the series orientation of fillers was more dominant in predicting elastic moduli of bionanocomposites at the ESO content of $60 \mathrm{wt} \%$ (error percentage: approximately 7\%). Additionally, according to $\mathrm{H}-\mathrm{T}$ model and $\mathrm{H}-\mathrm{S}$ model, aspect ratios of clay fillers in nanocomposites were found to increase with increasing the ESO content.

In addition, with respect to tensile strength as a function of clay content, D-T model, Lu model, and T-P-T model at $(B=3)$ had good partial agreement with experimental data of bionanocomposites with $5 \mathrm{wt} \%$ clay inclusion. In particular, the curve fitting of experimental data at clay contents from 0 to $5 \mathrm{wt} \%$ was reasonably good when T-P-T model was employed with empirical constant $B=8.693$ due to strong filler-matrix interfacial bonding.

When the effect of ESO content on tensile strengths of bionanocomposites was considered, selected models except D-T model and Lu model showed partially good fitting with experimental data. N-N model and T-P-T model $(B=0)$ fully fitted only experimental data of conventional nanocomposites (i.e., $0 \mathrm{wt} \%$ ESO). In contrast, T-P-T model matched better experimental data at the ESO contents of 20 and $40 \mathrm{wt} \%$ on account of strong filler-matrix interfacial bonding $(B=7.960)$. In addition, experimental data with $60 \mathrm{wt} \% \mathrm{ESO}$ did not fit all proposed models with a clear underestimation instead of the comparable fitted model because aspect ratios of fillers to enhance stress transfer between fillers and matrices were not involved in proposed theoretical models.

\section{Data Availability}

All data generated or analysed during this study are included in this manuscript.

\section{Conflicts of Interest}

The authors declare that they have no conflicts of interest and no financial interest related to this study.

\section{Acknowledgments}

H. Salam acknowledges the Directorate General of Resources for Science, Technology and Higher Education, Ministry of Research, Technology and Higher Education of the Republic Indonesia for funding this study through a PhD scholarship award (reference no. 4866/E4.4/K/2013).

\section{References}

[1] R. Mülhaupt, "Green polymer chemistry and bio-based plastics: dreams and reality," Macromolecular Chemistry and Physics, vol. 214, no. 2, pp. 159-174, 2013.

[2] S. S. Ray and M. Bousmina, "Biodegradable polymers and their layered silicate nanocomposites: in greening the 21st century materials world," Progress in Materials Science, vol. 50, no. 8, pp. 962-1079, 2005.

[3] D. Ratna and A. K. Banthia, "Epoxidized soybean oil toughened epoxy adhesive," Journal of Adhesion Science and Technology, vol. 14, no. 1, pp. 15-25, 2000. 
[4] S. G. Tan and W. S. Chow, "Curing characteristics and thermal properties of epoxidized soybean oil based thermosetting resin," Journal of the American Oil Chemists' Society, vol. 88, no. 7, pp. 915-923, 2011.

[5] S. J. Park, F. L. Jin, and J. R. Lee, "Effect of biodegradable epoxidized castor oil on physicochemical and mechanical properties of epoxy resins," Macromolecular Chemistry and Physics, vol. 205, no. 15, pp. 2048-2054, 2004.

[6] F. Jaillet, M. Desroches, R. Auvergne, B. Boutevin, and S. Caillol, "New biobased carboxylic acid hardeners for epoxy resins," European Journal of Lipid Science and Technology, vol. 115, no. 6, pp. 698-708, 2013.

[7] S. N. Khot, J. J. Lascala, E. Can et al., "Development and application of triglyceride-based polymers and composites," Journal of Applied Polymer Science, vol. 82, no. 3, pp. 703-723, 2001.

[8] P. Czub, "Application of modified natural oils as reactive diluents for epoxy resins," Macromolecular Symposia, vol. 242, no. 1, pp. 60-64, 2006.

[9] A. P. Gupta, S. Ahmad, and A. Dev, "Development of novel bio-based soybean oil epoxy resins as a function of hardener stoichiometry," Polymer-Plastics Technology and Engineering, vol. 49, no. 7, pp. 657-661, 2010.

[10] J. Zhang, S. Hu, G. Zhan, X. Tang, and Y. Yu, "Biobased nanocomposites from clay modified blend of epoxidized soybean oil and cyanate ester resin," Progress in Organic Coating, vol. 76, no. 11, pp. 1683-1690, 2013.

[11] S. G. Tan, Z. Ahmad, and W. S. Chow, "Interpenetrating polymer network structured thermosets prepared from epoxidized soybean oil/diglycidyl ether of bisphenol A," Polymer International, vol. 63, no. 2, pp. 273-279, 2014.

[12] M. D. Samper, R. Petrucci, L. Sanchez-Nacher, R. Balart, and J. M. Kenny, "Properties of composite laminates based on basalt fibers with epoxidized vegetable oils," Materials \& Design, vol. 72, pp. 9-15, 2015.

[13] S. C. Mauck, S. Wang, W. Ding et al., "Biorenewable tough blends of polylactide and acrylated epoxidized soybean oil compatibilized by a polylactide star polymer," Macromolecules, vol. 49, no. 5, pp. 1605-1615, 2016.

[14] P. Niedermann, G. Szebényi, and A. Toldy, "Effect of epoxidized soybean oil on curing, rheological, mechanical and thermal properties of aromatic and aliphatic epoxy resins," Journal of Polymers and the Environment, vol. 22, no. 4, pp. 525-536, 2014.

[15] A. Shabeer, S. Sundararaman, K. Chandrashekhara, and L. R. Dharani, "Physicochemical properties and fracture behavior of soy-based resin," Journal of Applied Polymer Science, vol. 105, no. 2, pp. 656-663, 2007.

[16] S. K. Sahoo, S. Mohanty, and S. K. Nayak, "Synthesis and characterization of bio-based epoxy blends from renewable resource based epoxidized soybean oil as reactive diluent," Chinese Journal of Polymer Science, vol. 33, no. 1, pp. 137152, 2015.

[17] D. Ratna, "Mechanical properties and morphology of epoxidized soyabean-oil-modified epoxy resin," Polymer International, vol. 50, no. 2, pp. 179-184, 2001.

[18] F. L. Jin and S. J. Park, “Thermomechanical behavior of epoxy resins modified with epoxidized vegetable oils," Polymer International, vol. 57, no. 4, pp. 577-583, 2008.

[19] M. Haq, R. Burgueño, A. K. Mohanty, and M. Misra, "Hybrid bio-based composites from blends of unsaturated polyester and soybean oil reinforced with nanoclay and natural fibers,"
Composites Science and Technology, vol. 68, no. 15-16, pp. 3344-3351, 2008.

[20] M. Shibata and K. Nakai, "Preparation and properties of biocomposites composed of bio-based epoxy resin, tannic acid, and microfibrillated cellulose," Journal of Polymer Science Part B: Polymer Physics, vol. 48, no. 4, pp. 425-433, 2010.

[21] J. P. Torres, R. Hoto, J. Andrés, and J. A. García-Manrique, "Manufacture of green-composite sandwich structures with basalt fiber and bioepoxy resin," Advances in Materials Science and Engineering, vol. 2013, Article ID 214506, 9 pages, 2013.

[22] V. Tanrattanakul and P. Saithai, "Mechanical properties of bioplastics and bioplastic-organoclay nanocomposites prepared from epoxidized soybean oil with different epoxide contents," Journal of Applied Polymer Science, vol. 114, no. 5, pp. 3057-3067, 2009.

[23] H. Uyama, M. Kuwabara, T. Tsujimoto, M. Nakano, A. Usuki, and S. Kobayashi, "Green nanocomposites from renewable resources: plant oil-clay hybrid materials," Chemistry of Materials, vol. 15, no. 13, pp. 2492-2494, 2003.

[24] Y. Takada, K. Shinbo, Y. Someya, and M. Shibata, "Preparation and properties of bio-based epoxy montomorillonite nanocomposites derived from polyglycerol polyglycidyl ether and e-polylysine," Journal of Applied Polymer Science, vol. 113, no. 1, pp. 479-484, 2009.

[25] R. Wang, T. Schuman, R. R. Vuppalapati, and K. Chandrashekhara, "Fabrication of bio-based epoxy-clay nanocomposites," Green Chemistry, vol. 16, no. 4, pp. 18711882, 2014.

[26] Z. S. Liu, S. Z. Erhan, and J. Xu, "Preparation, characterization and mechanical properties of epoxidized soybean oil/clay nanocomposites," Polymer, vol. 46, no. 23, pp. 10119-10127, 2005.

[27] S. Bourbigot, G. Fontaine, S. Bellayer, and R. Delobel, "Processing and nanodispersion: a quantitative approach for polylactide nanocomposite," Polymer Testing, vol. 27, no. 1, pp. 210, 2008.

[28] M. Haq, R. Burgueño, A. K. Mohanty, and M. Misra, "Processing techniques for bio-based unsaturated-polyester/clay nanocomposites: tensile properties, efficiency, and limits," Composites Part A Applied Science and Manufacturing, vol. 40, no. 4, pp. 394-403, 2009.

[29] F. Chivrac, E. Pollet, P. Dole, and L. Avérous, "Starch-based nano-biocomposites: plasticizer impact on the montmorillonite exfoliation process," Carbohydrate Polymers, vol. 79, no. 4, pp. 941-947, 2010.

[30] V. Ojijo and S. S. Ray, "Processing strategies in bionanocomposites," Progress in Polymer Science, vol. 38, no. 10-11, pp. 1543-1589, 2013.

[31] Q. Lv, Z. Wang, S. Chen, C. Li, S. Sun, and S. Hu, "Effects of single adatom and Stone-Wales defects on the elastic properties of carbon nanotube/polypropylene composites: a molecular simulation study," International Journal of Mechanical Sciences, vol. 131-132, pp. 527-534, 2017.

[32] X. Kornmann, H. Lindberg, and L. A. Berglund, "Synthesis of epoxy-clay nanocomposites: influence of the nature of the clay on structure," Polymer, vol. 42, no. 4, pp. 1303-1310, 2001.

[33] L. Wu, S. V. Hoa, T. Minh, and T. Ton, "Effects of composition of hardener on the curing and aging for an epoxy resin system," Journal of Applied Polymer Science, vol. 99, no. 2, pp. 580-588, 2006. 
[34] L. Liu and M. Li, "Curing mechanisms and kinetic analysis of DGEBA cured with a novel imidazole derivative curing agent using DSC techniques," Journal of Applied Polymer Science, vol. 117, no. 6, pp. 3220-3227, 2010.

[35] F. Wypych and K. G. Satyanarayana, "Functionalization of single layers and nanofibers: a new strategy to produce polymer nanocomposites with optimized properties," Journal of Colloid and Interface Science, vol. 285, no. 2, pp. 532-543, 2005.

[36] Y. Dong and D. Bhattacharyya, "Effects of clay type, clay/compatibiliser content and matrix viscosity on the mechanical properties of polypropylene/organoclay nanocomposites," Composites Part A Applied Science and Manufacturing, vol. 39, no. 7, pp. 1177-1191, 2008.

[37] C. Alzina, A. Mija, L. Vincent, and N. Sbirrazzuoli, "Effects of incorporation of organically modified montmorillonite on the reaction mechanism of epoxy/amine cure," The Journal of Physical Chemistry B, vol. 116, no. 19, pp. 5786-5794, 2012.

[38] R. Nakamura, A. N. Netravali, and M. V. Hosur, "Effect of halloysite nanotube incorporation in epoxy resin and carbon fiber ethylene/ammonia plasma treatment on their interfacial property," Journal of Adhesion Science and Technology, vol. 26, no. 8-9, pp. 1295-1312, 2012.

[39] Y. Dong and D. Bhattacharyya, "Investigation on the competing effects of clay dispersion and matrix plasticisation for polypropylene/clay nanocomposites. Part I: morphology and mechanical properties," Journal of Materials Science, vol. 47, no. 8, pp. 3900-3912, 2012.

[40] A. J. Bur, Y. H. Lee, S. C. Roth, and P. R. Start, "Measuring the extent of exfoliation in polymer/clay nanocomposites using real- time process monitoring methods," Polymer, vol. 46, no. 24, pp. 10908-10918, 2005.

[41] L. Wang, K. Wang, L. Chen, Y. Zhang, and C. He, "Preparation, morphology and thermal/mechanical properties of epoxy/nanoclay composite," Composites Part A Applied Science and Manufacturing, vol. 37, no. 11, pp. 1890-1896, 2006.

[42] J. M. Barbas, A. V. Machado, and J. A. Covas, "Evolution of dispersion along the extruder during the manufacture of polymer- organoclay nanocomposites," Chemical Engineering Science, vol. 98, pp. 77-87, 2013.

[43] A. Kaboorani, B. Riedl, and P. Blanchet, "Ultrasonication technique: a method for dispersing nanoclay in wood adhesives," Journal of Nanomaterials, vol. 2013, Article ID 341897, 9 pages, 2013.

[44] Y. Zare and H. Garmabi, "Thickness, modulus and strength of interphase in clay/polymer nanocomposites," Applied Clay Science, vol. 105-106, pp. 66-70, 2015.

[45] H. Miyagawa, A. Mohanty, L. T. Drzal, and M. Misra, "Effect of clay and alumina-nanowhisker reinforcements on the mechanical properties of nanocomposites from biobased epoxy: a comparative study," Industrial \& Engineering Chemistry Research, vol. 43, no. 22, pp. 7001-7009, 2004.

[46] Q. H. Zeng, A. B. Yu, and G. Q. Lu, "Multiscale modeling and simulation of polymer nanocomposites," Progress in Polymer Science, vol. 33, no. 2, pp. 191-269, 2008.

[47] W. Voigt, "Ueber die Beziehung zwischen den beiden Elasticitätsconstanten isotroper Körper," Annalen der Physik, vol. 274, no. 12 , pp. $573-587,1889$.

[48] A. Reuss, "Berechnung der Fließgrenze von Mischkristallen auf Grund der Plastizitätsbedingung für Einkristalle .," Zeitschrift für Angewandte Mathematik und Mechanik, vol. 9, no. 1 , pp. 49-58, 1929.
[49] "Technical information of L13 epoxy resin," Adhesive Engineering Pty, NSW, Australia, October 2019, http:// adhesiveengineering.com.au/wp-content/uploads/2013/03/ L13-TB.pdf.

[50] "Technical information of DGEBA resin," National Centre for Biotechnology Information, PubChem Compound Database, October 2019, https://pubchem.ncbi.nlm.nih.gov/compound/ Bisphenol-A-diglycidyl-ether.

[51] "Technical information of ESO," Zhejiang Jiaao Enprotech Stock Co., Ltd., Zhejiang, China, October 2019, http://www .jiaaohuanbao.com/en/product_detail.php?sid=71\&cid= $7 \& \mathrm{id}=44$.

[52] “Technical information of ESBO," National Centre for Biotechnology Information, PubChem Compound Database, October 2019, https://pubchem.ncbi.nlm.nih.gov/compound/ 71306824.

[53] "Technical data sheet of Cloisite: organically modified phyllosilicates for thermoplastics BYK additives," October 2019, https://www.byk.com/en/additives/additives-by-name/cloisite .php.

[54] T. D. Fornes and D. R. Paul, "Modeling properties of nylon 6/clay nanocomposites using composite theories," Polymer, vol. 44, no. 17, pp. 4993-5013, 2003.

[55] D. A. Brune and J. Bicerano, "Micromechanics of nanocomposites: comparison of tensile and compressive elastic moduli, and prediction of effects of incomplete exfoliation and imperfect alignment on modulus," Polymer, vol. 43, no. 2, pp. 369387, 2002.

[56] H. Salam and Y. Dong, "Property evaluation and material characterization of soybean oil modified bioepoxy/clay nanocomposites for environmental sustainability," Materials Today Sustainability, vol. 5, p. 100012, 2019.

[57] C. Y. Hui and D. Shia, "Simple formulae for the effective moduli of unidirectional aligned composites," Polymer Engineering and Science, vol. 38, no. 5, pp. 774-782, 1998.

[58] Y. P. Wu, Q. X. Jia, D. S. Yu, and L. Q. Zhang, "Modeling Young's modulus of rubber-clay nanocomposites using composite theories," Polymer Testing, vol. 23, no. 8, pp. 903-909, 2004.

[59] V. R. Riley, "Interaction effects in polymer composites," in Polymer Conference Series, University of Utah, Salt Lake City, 1970.

[60] G. E. Padawer and N. Beecher, "On the strength and stiffness of planar reinforced plastic resins," Polymer Engineering and Science, vol. 10, no. 3, pp. 185-192, 1970.

[61] T. J. Hirsch, "Modulus of elasticity of concrete affected by elastic moduli of cement paste matrix and aggregate," Proceedings of American Concrete Institute, vol. 59, no. 3, pp. 427-452, 1962.

[62] J. C. Halpin, "Stiffness and expansion estimates for oriented short fiber composites," Journal of Composite Materials, vol. 3, no. 4, pp. 732-734, 1969.

[63] J. C. Halpin Affdl and J. L. Kardos, "The Halpin-Tsai equations: a review," Polymer Engineering and Science, vol. 16, no. 5, pp. 344-352, 1976.

[64] D. Qian, E. C. Dickey, R. Andrews, and T. Rantell, "Load transfer and deformation mechanisms in carbon nanotubepolystyrene composites," Applied Physics Letters, vol. 76, no. 20, pp. 2868-2870, 2000.

[65] P. K. Mallick, Fiber-Reinforce Composites: Materials, Manufacturing, and Design, CRC Press, Boca Raton, 3rd edition, 2007. 
[66] D. Shia, C. Y. Hui, S. D. Burnside, and E. P. Giannelis, "An interface model for the prediction of Young's modulus of layered silicate-elastomer nanocomposites," Polymer Composites, vol. 19, no. 5, pp. 608-617, 1998.

[67] D. Hull and T. W. Clyne, An Introduction to Composite Materials, Cambridge University Press, Cambridge, 2nd edition, 1996.

[68] M. Van Es, F. Xiqiao, J. van Turnhout, and E. van der Giessen E, "Comparing polymer-clay nanocomposites with conventional composites using composite modelling," in Specialty Polymer Additives: Principles and Applications, S. Al-Malaika, A. Golovoy, and C. A. Wilkie, Eds., pp. 391-414, Blackwell Science Publishers, Oxford, 2001.

[69] F. Danusso and G. Tieghi, "Strength versus composition of rigid matrix particulate composites," Polymer, vol. 27, no. 9, pp. 1385-1390, 1986.

[70] A. Delesse, "Procédé mécanique pour déterminer la composition des roches," Annales des Mines, vol. 13, pp. 379-388, 1848.

[71] L. Nicolais and M. Narkis, "Stress-strain behavior of styreneacrylonitrile/glass bead composites in the glassy region," Polymer Engineering and Science, vol. 11, no. 3, pp. 194-199, 1971.

[72] S. Lu, L. Yan, X. Zhu, and Z. Qi, "Microdamage and interfacial adhesion in glass bead-filled high-density polyethylene," Journal of Materials Science, vol. 27, no. 17, pp. 4633-4638, 1992.

[73] B. Turcsányi, B. Pukánszky, and F. Tüdõs, "Composition dependence of tensile yield stress in filled polymers," Journal of Materials Science Letters, vol. 7, no. 2, pp. 160-162, 1988.

[74] B. R. B. Kumar, S. E. Zeltmann, M. Doddamani, N. Gupta, U. S. Gurupadu, and R. R. N. Sailaja, "Effect of cenosphere surface treatment and blending method on the tensile properties of thermoplastic matrix syntactic foams," Journal of Applied Polymer Science, vol. 133, no. 35, 2016.

[75] A. R. Zanjanijam, M. Bahrami, and M. Hajian, "Poly(vinyl chloride)/single wall carbon nanotubes composites: investigation of mechanical and thermal characteristics," Journal of Vinyl \& Additive Technology, vol. 22, no. 2, pp. 128-133, 2016.

[76] T. A. Praveen, J. Sundara Rajan, and R. R. N. Sailaja, "Comparative study of dielectric and mechanical properties of HDPEMWCNT- $\mathrm{SiO}_{2}$ nanocomposites," Materials Research Bulletin, vol. 83, pp. 294-301, 2016.

[77] S. Pavlidou and C. D. Papaspyrides, "A review on polymerlayered silicate nanocomposites," Progress in Polymer Science, vol. 33, no. 12, pp. 1119-1198, 2008.

[78] S. Y. Fu, X. Q. Feng, B. Lauke, and Y. W. Mai, "Effects of particle size, particle/matrix interface adhesion and particle loading on mechanical properties of particulate-polymer composites," Composites Part B Engineering, vol. 39, no. 6, pp. 933961, 2008. 


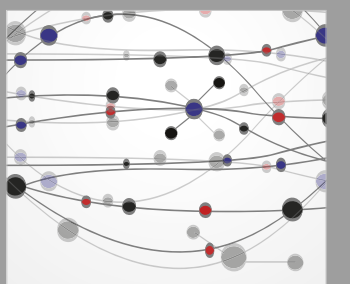

The Scientific World Journal
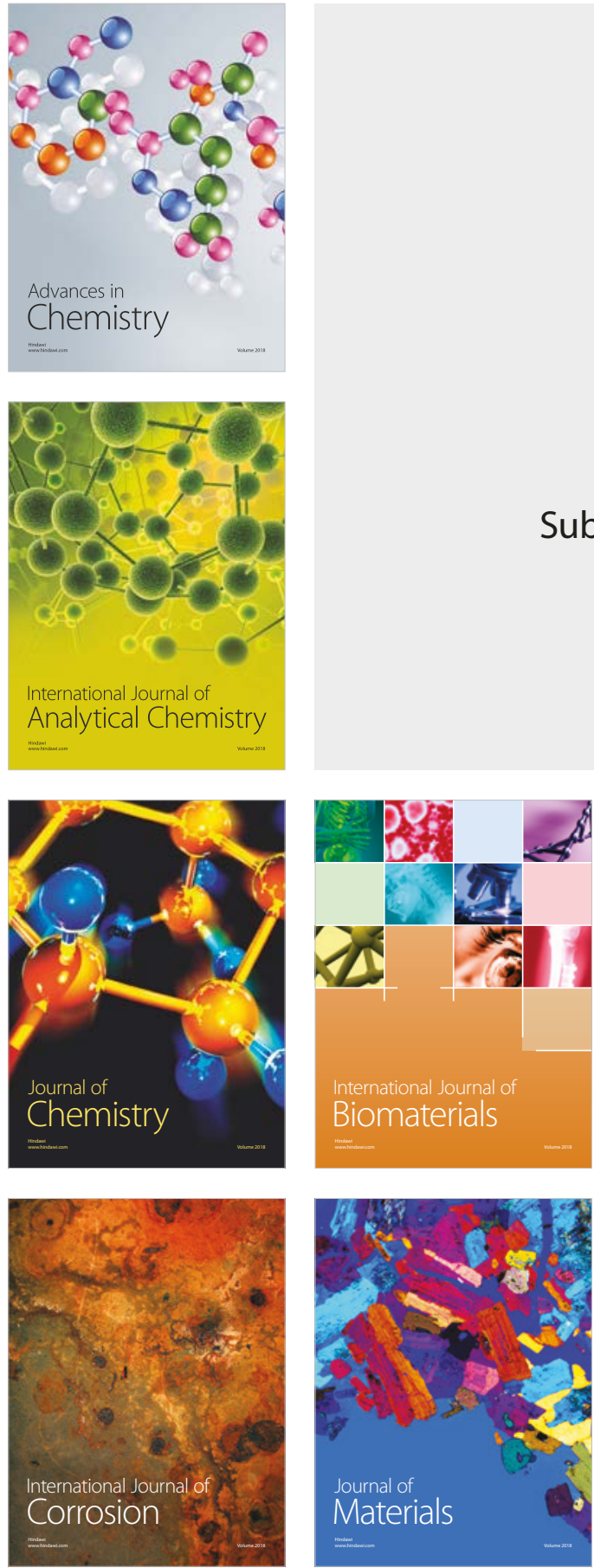

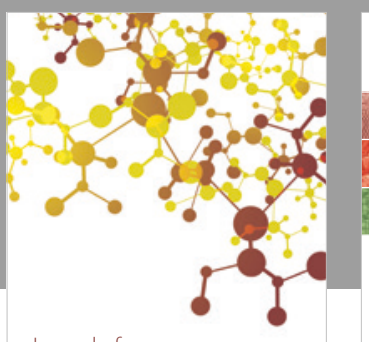

Journal of

Applied Chemistry
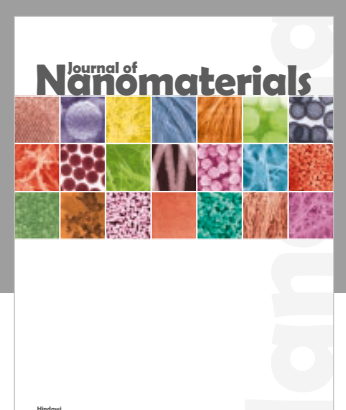

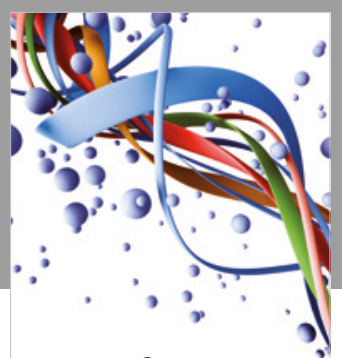

Scientifica

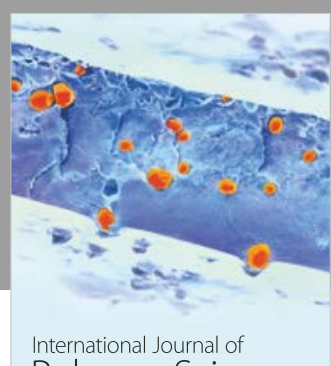

Polymer Science

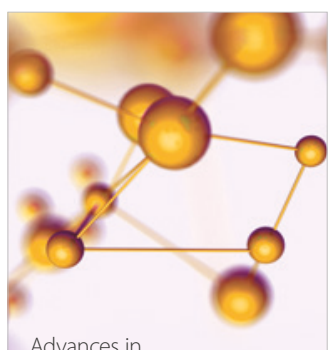

Physical Chemistry
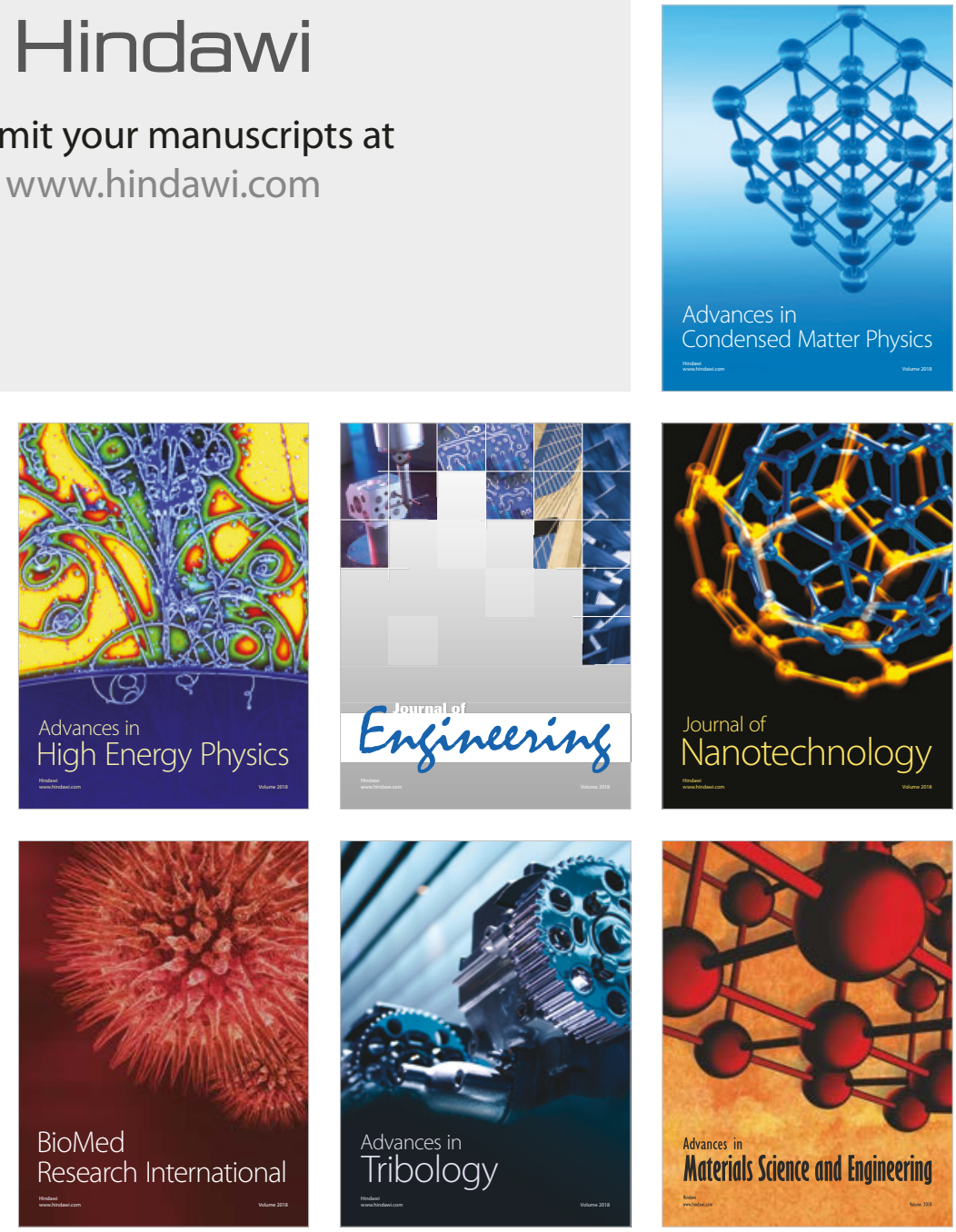